Cómo citar este trabajo: Fernández Portela, J., \& Vidal Domínguez, M. J. (2020). Wine routes as engines of socio-territorial dynamisation: the case of Castilla y León. Boletín de la Asociación de Geógrafos Españoles, 84, 2789, 1-36. hittps://doi.org/10.21138/bage.2789

\title{
Las rutas del vino como motores de dinamización socio-territorial: el caso de Castilla y León
}

Wine routes as engines of socio-territorial dynamisation:

the case of Castilla y León

\section{Julio Fernández Portela}

jfportela@geo.uned.es

Miembro del Grupo de Investigación Geografía, Paisaje y Tecnologías de la Información

Departamento de Geografía

Universidad Nacional de Educación a Distancia (UNED) (España)

\author{
María Jesús Vidal Domínguez \\ mariajesus.vida@uam.es \\ Departamento de Geografía \\ Universidad Autónoma de Madrid (España)
}

\section{Resumen}

El mundo rural y, en especial, Castilla y León, se encuentra inmerso en un proceso de abandono y envejecimiento poblacional que se está haciendo insostenible en algunos territorios ante la falta de oportunidades laborales y la desaparición de servicios básicos. La puesta en marcha de iniciativas turísticas, principalmente relacionadas con el enoturismo, se configura como una actividad económica clave para lograr el desarrollo rural, además de la diversificación económica. Para ello se apoya en el entramado que se genera en torno al vino, que, además, va a aprovechar el resto 
de potencialidades presentes en el espacio para ofrecer un producto turístico diversificado y para todo tipo de públicos. En este artículo se va a mostrar el panorama nacional del enoturismo y especialmente de las Rutas del Vino, su impacto en el desarrollo rural, y posteriormente se va a analizar la situación particular de la Comunidad de Castilla y León. Para ello se utilizarán los informes de ACEVIN y la información propia de las páginas web de las Rutas del Vino.

Palabras clave: Rutas del vino; enoturismo; Castilla y León; desarrollo rural; territorio.

\section{Abstract}

The rural world and, especially, Castilla y León, is immersed in a process of population abandonment and aging that is becoming unsustainable in some territories due to the lack of job opportunities and the disappearance of basic services. The implementation of tourism initiatives, mainly related to wine tourism, is configured as a key economic activity to achieve rural development, in addition to economic diversification. For this, it is based on the framework that is generated around wine, which, in addition, will take advantage of the rest of the potential present in the space to offer a diversified tourist product and for all types of public. This article will show the national landscape of wine tourism and especially the wine routes, its impact on rural development, and then analyze the particular situation of the Community of Castilla y León. For this purpose, ACEVIN reports and the information of the web pages of the wine routes will be used.

Key words: Routes of wine; wine tourism; Castilla y León; rural development; territory.

\section{Introducción}

El sector agrario ha sido la base económica del medio rural durante siglos. La población vivía directamente de los trabajos realizados en el campo como la agricultura, la ganadería o la actividad forestal entre otras. El punto de inflexión se produjo con la revolución industrial, momento a partir del cual, la población fue trasladándose del campo a la ciudad a la búsqueda de una mejor calidad de vida y un salario fijo (Zárate Martín \& Rubio Benito, 2005). Este movimiento de población se fue incrementando con el paso de los años y, desde mediados del siglo XX, en el caso español, se intensificó provocando un importante éxodo rural que continua en la actualidad con un fuerte vaciamiento de las zonas rurales (Delgado Urrecho \& Martínez Fernández, 2017). Hoy día, este problema es uno de los principales retos a los que deben enfrentarse las administraciones públicas, los políticos y los geógrafos entre otros profesionales, y en especial en Castilla y León, con el objetivo de intentar frenar la sangría de efectivos que abandonan, ya no 
solo las áreas rurales, sino también algunas ciudades e incluso capitales de provincia, donde cada vez hay una mayor escasez de oportunidades laborales y carencia de servicios básicos.

En la región de Castilla y León, la economía de los espacios rurales se basa en la actividad agraria y, en concreto, en la agricultura con la producción de cereal, en especial trigo y cebada como producto clave para su desarrollo socioeconómico. Junto a estos cultivos, el viñedo y la elaboración de vino, también configuran una actividad agroindustrial que se ha convertido en el motor económico en numerosas poblaciones de los principales valles fluviales de la región. Los más significativos son los de la Cuenca Hidrográfica del Duero, con el propio río Duero a la cabeza con Denominaciones de Origen (DO) como Ribera del Duero, Rueda, Toro o Arribes. Se constituye como un elemento vertebrador del espacio, recorriendo estas tierras de Este a Oeste, desde la provincia de Soria hasta Portugal, emplazándose la mayor parte de las 75436 hectáreas $^{1}$ existentes en la región en el año 2016 por sus terrazas fluviales (el viñedo representa el 80,61 \% de los cultivos leñosos). Estos viñedos se prolongan por el territorio portugués, pasando de situarse en las terrazas, más o menos llanas o con poca pendiente (Fernández Portela, 2014), a espacios más escarpados que requieren el uso de bancales para poder cultivarse hasta casi su desembocadura en el Océano Atlántico. Junto al Duero hay que señalar el papel tan destacado de algunos de sus afluentes como el Pisuerga (DO Cigales), el Arlanza (DO Arlanza) o el Esla (DO Valles de Benavente y DO Tierra de León), y que ocupan las terrazas cuaternarias que han labrado estos ríos con el paso del tiempo. Además de la cuenca del Duero hay que añadir los viñedos del Bierzo que pertenecen a la Cuenca Hidrográfica del Miño-Sil.

El cultivo de la vid cuenta con una historia en la Península lbérica que supera los dos mil años (Piqueras Haba, 2014), y que por lo tanto, se ha ido arraigando en el paisaje y en el paisanaje. El trabajo en los viñedos y la posterior transformación de la uva en vino, se han convertido en un empuje socioeconómico clave en algunas regiones tras la realización de importantes inversiones en la plantación de nuevas vides y la construcción de grandes bodegas. Estas iniciativas han repercutido en el desarrollo rural de pequeñas y medianas localidades, lo que las ha permitido orientar su actividad económica hacia el cultivo de la vid y la elaboración de vino, y con el paso de los años, han aprovechado este producto para diversificar su estructura económica hacia otros sectores vinculados con el mundo del vino, en especial, con el enoturismo.

1 Datos procedentes del Anuario de Estadística Agraria de Castilla y León (2016). Consejería de Agricultura y Ganadería de la Junta de Castilla y León. 
Es aquí donde se enmarcan las Rutas del Vino como un conjunto de entidades que se encargan de gestionar y planificar los recursos existentes en determinadas comarcas vitivinícolas, en este caso de Castilla y León, con el objetivo de crear una serie de productos turísticos que contribuyan al desarrollo rural, a la diversificación económica y al mantenimiento del medio rural (Figura 1).

Para ello es necesario el trabajo conjunto de las administraciones públicas, principalmente locales, y de empresarios privados, que sean capaces de generar nuevas gobernanzas rurales más eficaces, eficientes y de mayor calidad (Woods, 2005). Para alcanzar estos fines es necesario el diseño de estrategias de diversificación económica que tengan como producto central el vino, con las bodegas y los viñedos, pero integrando otras actividades económicas vinculadas con la hostelería como son los bares, restaurantes y alojamientos, las enotecas, las tiendas de productos alimentarios, las empresas de transportes, y otras iniciativas que pretendan alcanzar la revalorización y la conservación del patrimonio, de la cultura y de la naturaleza. Todo ello permite conseguir una mejor cohesión territorial entre los municipios de las comarcas vitivinícolas favoreciendo un acceso más equitativo a los servicios y configurando proyectos con intereses comunes que permitan la articulación del espacio geográfico. De esta forma, a su vez, se aprovechan las potencialidades de cada uno de los territorios y se pueden establecer lazos de unión y colaboración entre ellos configurando unas señas de identidad propias, específicas y únicas que van a ser la base para la creación de marcas territoriales (branding territorial) (Nogué i Font \& San Eugenio Vela, 2017).

\section{Figura 1. Principales comarcas vitivinícolas y sus logos}

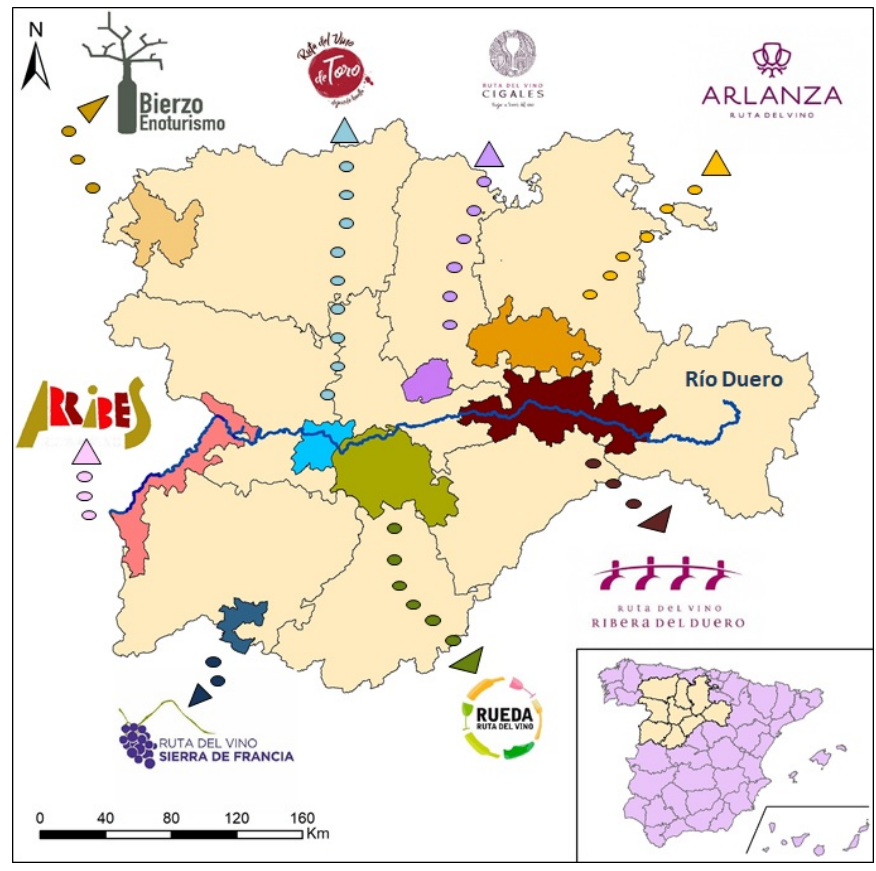

Fuente: elaboración propia basada en Consejos Reguladores y Rutas del Vino 


\section{El papel del enoturismo en el desarrollo rural}

El medio rural de Castilla y León atraviesa en la actualidad una problemática que está afectando a todo el sistema socio-económico. La población abandona, ya no solo los núcleos rurales, sino también los urbanos, hacia otras comunidades autónomas a causa de la baja productividad y la constante dificultad para la creación de empleo (García Fernández, 2016). A este problema hay que sumar el intenso proceso de envejecimiento en el que se encuentra este territorio, pues es la población joven la que emigra, y lo que hace es recrudecer la delicada situación de este espacio geográfico. Un problema que lleva latente en esta región más de medio siglo, y que tiene sus orígenes en las generaciones huecas que trajo consigo la Guerra Civil y posteriormente con la emigración de los años sesenta y setenta del siglo XX, en especial de la femenina (González González, 1997; Del Rey Poveda, Cebrián \& Ortega, 2009) desarticulando la estructura territorial, política, social y económica de la región.

En la actualidad, lejos de haber encontrado una solución al problema, se ha acrecentado, pues Castilla y León cada vez está más envejecida y más despoblada, inmersa en un claro proceso de involución demográfica (Vidal Domínguez \& Fernández Portela, 2014). Por estos motivos, es necesaria la búsqueda de nuevas posibilidades de desarrollo económico, en especial en el medio rural, con el objetivo de intentar frenar la sangría poblacional que, según datos del INE (Instituto Nacional de Estadística), parecen indicar que se seguirá produciendo. ${ }^{2}$

Para ello, el turismo se convierte en una actividad clave para el desarrollo rural. La heterogeneidad de tipologías turísticas existentes en el turismo de interior es muy amplia (Valenzuela Rubio, 1997; Pardo Abad, 2013), pues abarca el cultural, el gastronómico, de aventura y deportivo, de naturaleza, y con una presencia cada vez más representativa del enoturismo ${ }^{3}$ o turismo del vino (Fernández Fernández \& Fernández Portela, 2019). El cultivo y la posterior transformación de un producto primario, en este caso las uvas, está dando lugar a la organización de rutas, eventos y

2 La población en Castilla y León en 1998 era de 2484603 y en el año 2018 de 2409164 según las estadísticas del Padrón continuo a 1 de enero de 1998 y 2018 respectivamente, es decir, 75439 habitantes menos. Por otro lado, el porcentaje de población de más de 65 años se ha incrementado, pasando de un 21,27\% (1998) a un $25,06 \%(2018)$.

3 Vintur (2005) define enoturismo como "el desarrollo de las actividades turísticas y de ocio y tiempo libre dedicadas al descubrimiento y disfrute cultural y enológico de la viña, el vino y su territorio". López Sánchez (2010) lo define como "una diversificación del turismo cultural, urbano y rural. (...) un producto integrado basado en las actividades vitícolas, gastronómicas y culturales, acompañado por una amplia oferta de alojamientos con servicios relacionados con dicha actividad (enotecas, vinotecas, vinoterapias, museos del vino, etc.) así como de una amplia oferta de actividades complementarias como golf, hípica, oferta comercial nocturna, ..." (p. 32). 
actividades de carácter turístico que pretenden promocionar, no solo el producto en cuestión, sino el resto de recursos existentes en un territorio ayudando a su enriquecimiento y fortalecimiento (Getz, 2000; Hall \& Mitchell, 2008; Miranda Escolar \& Fernández Morueco, 2011, Cordeiro Gonçalves, 2012; Millán Vázquez de la Torre \& Dancausa Millán, 2012). Con ello se consigue la diversificación económica del medio rural, la generación de rentas complementarias y, en algunas ocasiones, fijar la población.

Desde la década de los noventa del siglo XX comenzó a replantearse la idea del campo como un espacio orientado exclusivamente a la producción de alimentos destinados al consumo de la población. Se empezó a plantear la posibilidad de llevar a cabo nuevas actividades económicas, culturales, sociales y ecológicas relacionadas con los productos y otros recursos existentes en este medio para diversificar su economía (Millán Escriche, 2012; Correira \& Brito, 2016; Plaza Tabasco, Cañizares Ruiz \& Ruiz Pulpón, 2017) y evitar de esta forma la pérdida continuada de población, así como llevar a cabo medidas de protección medioambiental, la puesta en valor y conservación de su cultura y de su patrimonio que en muchos casos estaba desapareciendo, así como mejoras en las infraestructuras de las localidades donde se realizan este tipo de proyectos provocando la revalorización de las zonas rurales y mejorando la accesibilidad a ciertos servicios básicos para la población (Ponce Sánchez, 2009; Hortelano Mínguez, 2015).

La actividad agraria, base de la economía de estas poblaciones, va a continuar teniendo un papel destacado, pues es la responsable de producir la materia prima utilizada para la transformación de los productos agroalimentarios. Esta clase de alimentos se está consolidando como la base de una representativa tipología de turismos que se desarrollan, predominantemente, en el medio rural, y que al mismo tiempo aprovechan el resto de potencialidades existentes en el territorio para completar esta oferta turística. Como ejemplos destacados se encuentran productos como el café en el valle colombiano del Quindio además de contar con una rica y atrayente biodiversidad climática, paisajística, de fauna, de flora y de cultura (Ramírez Montañez, 2014), las manzanas en Brasil (Goulart Rocha \& Tulla, 2015), los olivos en la provincia española de Jaén (Sánchez Martínez \& Ortega Ruiz, 2016), o el potencial agroturístico que tiene la producción de cítricos en el Estado Libre y Soberano de Nuevo León en Méjico (Alcalá Escamilla \& López López, 2017).

El caso de las uvas y su transformación en vino es especial, pues el interés por este producto es mucho más amplio y ha dado lugar a una variedad de turismo en continua renovación, expansión y crecimiento conocido como enoturismo o turismo del vino presente en numerosas comarcas vitivinícolas del planeta como en la región canadiense de Niágara en Ontario (Carmichael, 2005), 
en España la DO de Jerez (López Sánchez, 2010) o el conjunto de Cataluña (Molleví Bortoló \& Fusté Forné, 2016) o en Sudáfrica (Ferreira \& Hunter, 2017). Este tipo de turismo es capaz de englobar e interrelacionar entre sí a los tres sectores económicos (Figura 2), lo que implica una estrecha colaboración con los diversos agentes del territorio para ofrecer un producto global e integrador.

Figura 2. Relación de los sectores económicos con el enoturismo

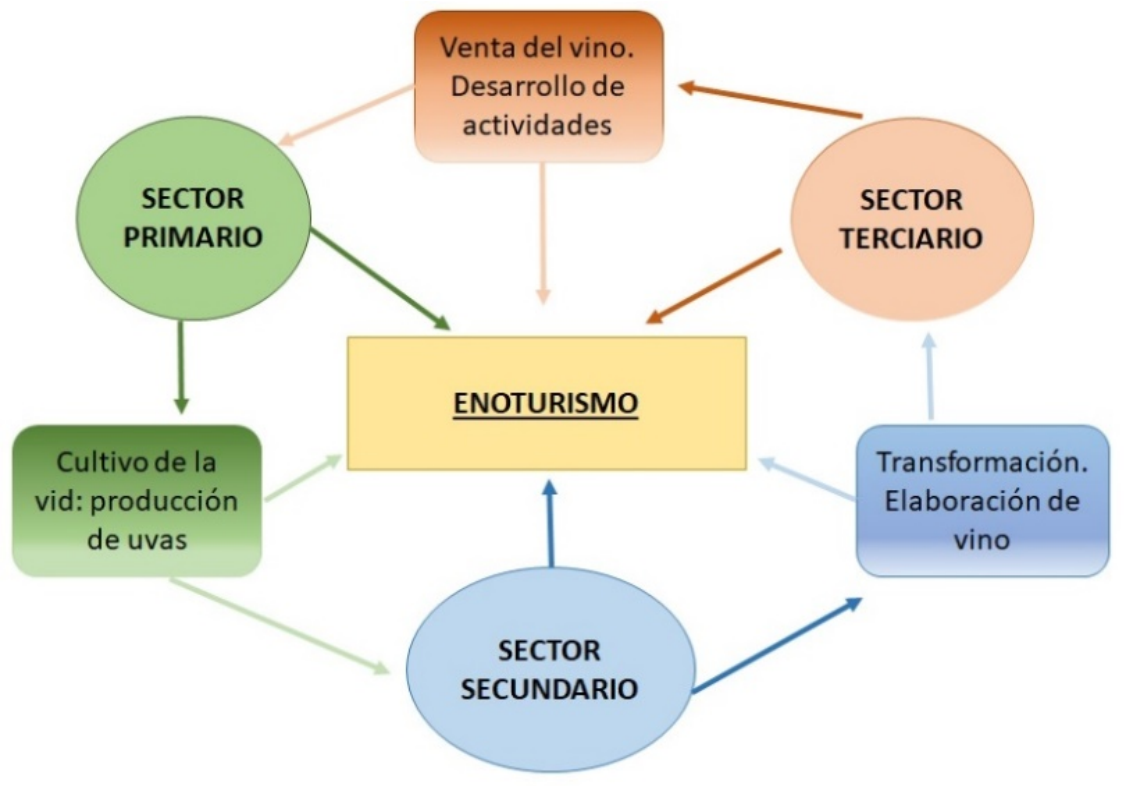

Fuente: elaboración propia

A ello hay que añadir otros atractivos relacionados directa e indirectamente con el mundo del vino que ayudan a crear un producto turístico integrado por el paisaje, el arte, la cultura o las tradiciones (Mitchell \& Hall, 2006). Más recientemente, algunos investigadores establecen una vinculación clave con la gastronomía como un potente factor de atracción de turistas convirtiéndose junto con el enoturismo en el motivo principal del viaje y no como un recurso complementario (Rodríguez García, López-Guzmán y Sánchez Cañizares, 2010). Todo ello en su conjunto converge para ofrecer una experiencia destinada al entretenimiento y disfrute de los visitantes, una forma diversa de ver el mundo rural, al mismo tiempo que va a suponer un impulso muy significativo para su desarrollo y la diversificación económica.

Los estudios sobre el turismo del vino tienen su origen en Australia y Nueva Zelanda a mediados de la década de los noventa del siglo XX (Beverland \& Bretherton, 1998; Hall \& Macionis, 1998) y su objetivo era estudiar la repercusión en el medio rural, por lo que la preocupación por este tipo de espacios no es una cuestión nueva ni exclusiva del territorio español, ni del europeo. Este interés se fue extendiendo a otros países de mundo donde el cultivo de la vid era significativo 
como por ejemplo en Chile (Sharples, 2002), Sudáfrica (Bruwer, 2003) y, en especial, en el continente europeo. En este último caso el problema del abandono del medio rural y el envejecimiento se ha ido agravando con el tiempo, por lo que se han puesto en marcha numerosas iniciativas con la finalidad de paliar o, en algunos casos, revertir los efectos tan negativos sobre el espacio rural en países como Francia (Frochot, 2000), España (Vieria Rodríguez, López-Guzmán \& Rodríguez García, 2012) e Italia (Cinelli Colombini, 2015), los tres principales países del mundo en cuanto a superficie de viñedo y producción de vino.

El papel tan destacado que ha ido adquiriendo el enoturismo ha hecho necesaria la planificación y gestión de esta actividad. Se han puesto en marcha diversas propuestas con el objetivo de promocionar, además de los vinos, los territorios en los que se elabora este producto, poniendo en valor el resto de recursos bajo la integración de un mismo concepto temático que favoreciera la diversificación económica de un territorio y el desarrollo local de los municipios en los que se desempeña (García López, 2008).

Por este motivo y en diferentes escalas, nacional e internacional, se han formado una serie de asociaciones y de redes que persiguen este fin (Figura 3) las cuales establecen lazos de cooperación entre los distintos organismos y territorios que las conforman. Tienen en común aspectos como la existencia de un producto de calidad enclavado en un espacio emblemático, la autenticidad y la sostenibilidad, y su objetivo es darlo a conocer y promocionarlo. Todas ellas juegan un papel esencial, pues entre unas y otras van a tejer una amplia malla de espacios al servicio del territorio, de las administraciones públicas, de las empresas privadas y de los ciudadanos del medio rural más desfavorecido, y van a presentar unos objetivos muy similares.

A nivel mundial se encuentran las Great Wine Capitals (Grandes Capitales del Vino), una red formada por comarcas vitivinícolas internacionales ${ }^{4}$ que persiguen la excelencia turística y que comparten valores económicos y culturales en torno al vino. Una línea similar, pero en esta ocasión en el continente europeo es la Red Europea de Ciudades del Vino (RECEVIN) ${ }^{5}$ que tienen como principales metas la defensa, de forma conjunta, de los intereses que poseen las administraciones locales europeas vinculadas económicamente al mundo del vino, el desarrollo de proyectos y el fomento y la difusión de las actividades que se están llevando a cabo en los diversos territorios que conforman esta red de ciudades del vino.

4 Rutas del Vino de España. Retrieved from https://www.wineroutesofspain.com/ver/2711/El-Club-de-ProductoRutas-del-Vino-de-Espa\%C3\%B1a.html

5 Recevin. Retrieved from http://www.recevin.eu/ 


\section{Figura 3. Principales redes vitivinícolas}

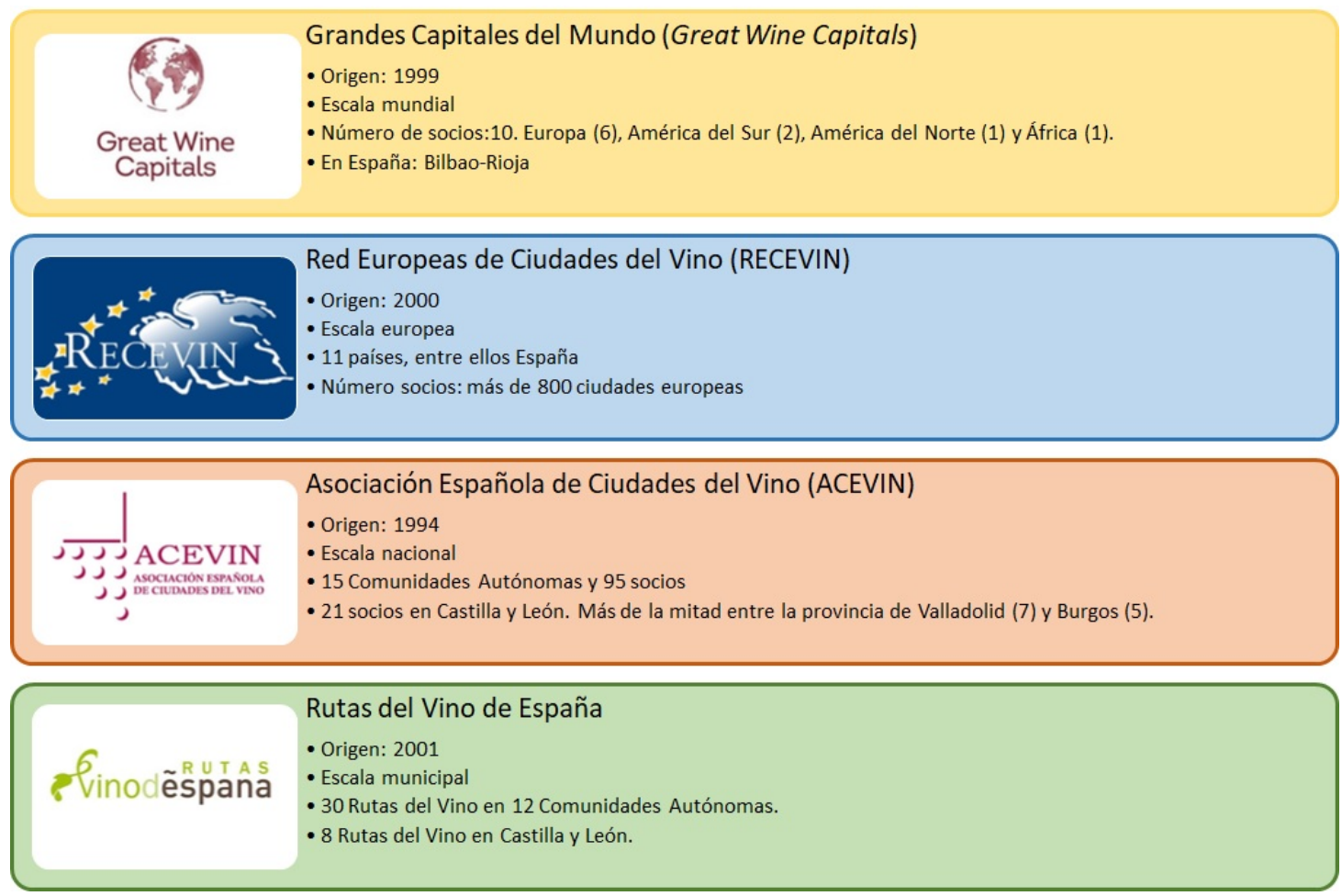

Fuente: elaboración propia a partir de Great Wine Capitals,

RECEVIN, ACEVIN y Rutas del Vino de España

En el caso español la Asociación de Ciudades del Vino (ACEVIN) ${ }^{6}$ consigue llegar a municipios de menor entidad lo que permite estar presente en una superficie más amplia del territorio donde las iniciativas anteriores no pueden llegar, además de incidir de forma directa en los verdaderos protagonistas. Su propósito es el de disponer de un espacio y de instrumentos de reflexión, principalmente para ayuntamientos y asociaciones, que contribuyan a realizar un análisis estratégico que favorezca la toma de decisiones y la realización de propuestas de promoción y diversificación económica local.

Finalmente se encuentran las Rutas del Vino, entidades socio-territoriales que presentan estrategias de desarrollo integral del territorio a través de una serie de itinerarios en zonas productoras de vino de calidad. Pretenden ser una vía que contribuya a diversificar la oferta vinculada a este producto para convertirse en un sector decisivo del medio rural (Miranda Escolar \& Fernández Morueco, 2011). Es un proyecto que surge gracias a $A C E V I N$, y que está apoyado por los Ministerios de Industria, Comercio y Turismo y el Ministerio de Agricultura, Pesca y Alimentación del Gobierno de España. Su objetivo principal es establecer relaciones de cooperación entre 
diferentes entidades y empresas (públicas y privadas) como son las bodegas, restaurantes y hoteles, consejos reguladores, museos o ayuntamientos entre un variado listado de socios, y que ofrecen programas turísticos novedosos y diferentes al tradicional y característico turismo de sol y playa propio del país, por lo que permiten:

descubrir al viajero una España diferente y vivir experiencias únicas. Las Rutas del Vino de España están emplazadas en territorios vitivinícolas que desde hace años trabajan (...) para generar experiencias memorables para los viajeros que buscan un nuevo concepto de turismo basado en la cultura del vino. ${ }^{7}$

El presente estudio se encuadra en una escala municipal, un marco de trabajo adecuado para la puesta en marcha de iniciativas que contribuyan al desarrollo del medio rural. Las iniciativas que se llevan a cabo tienen repercusión directa en los pequeños municipios que son los que más sufren el envejecimiento, la despoblación, la ausencia de servicios básicos y la escasez de actividades económicas. Por este motivo, han sido numerosas las iniciativas europeas, principalmente a través de programas como el PRODER y el LEADER (Fernández Portela, 2011; Hortelano Mínguez, 2015), así como la inversión privada, enfocado todo ello hacia los pequeños núcleos rurales con el objetivo de financiar proyectos que contribuyan a su revitalización socioeconómica.

\section{Metodología}

\subsection{La Comunidad de Castilla y León: una región extensa y despoblada}

La Comunidad Autónoma de Castilla y León posee una superficie total de 94223 Km² (2018), la de mayor extensión de España, no así en lo relativo a la cantidad de población que en ella habita, tan sólo 2409164 habitantes, un -4,39\% respecto al 2013, la pérdida más alta de todas las comunidades autónomas, lo que da lugar a una densidad de población muy baja de 25,6 habitantes por $\mathrm{Km}^{2}$ frente a la media nacional que se sitúa en 92,3 en el año 2018. Dichos habitantes están repartidos entre 2248 municipios de las nueve provincias que configuran la comunidad. El reparto de las entidades poblacionales por provincias está fuertemente polarizado. Hay muchos municipios de tamaño muy pequeño y al otro lado, tenemos pocos municipios de tamaño medio, la mayoría son las capitales de su respectiva provincia.

7 Rutas del Vino de España: https://www.wineroutesofspain.com/ver/2711/El-Club-de-Producto-Rutas-del-Vinode-Espa\%C3\%B1a.html 
El 89 \% de los 2248 municipios que conforman la Comunidad de Castilla y León en el año 2018 (Figura 4), tenían menos de 1000 habitantes, de ellos algo más de la mitad vivía en núcleos de entre 100 y 500 habitantes, y el 30,6\% en municipios de menos de 100 vecinos.

Figura 4. Distribución de la población de la Comunidad de Castilla y León por municipios y Grandes Áreas Urbanas (GAU) en el 2018

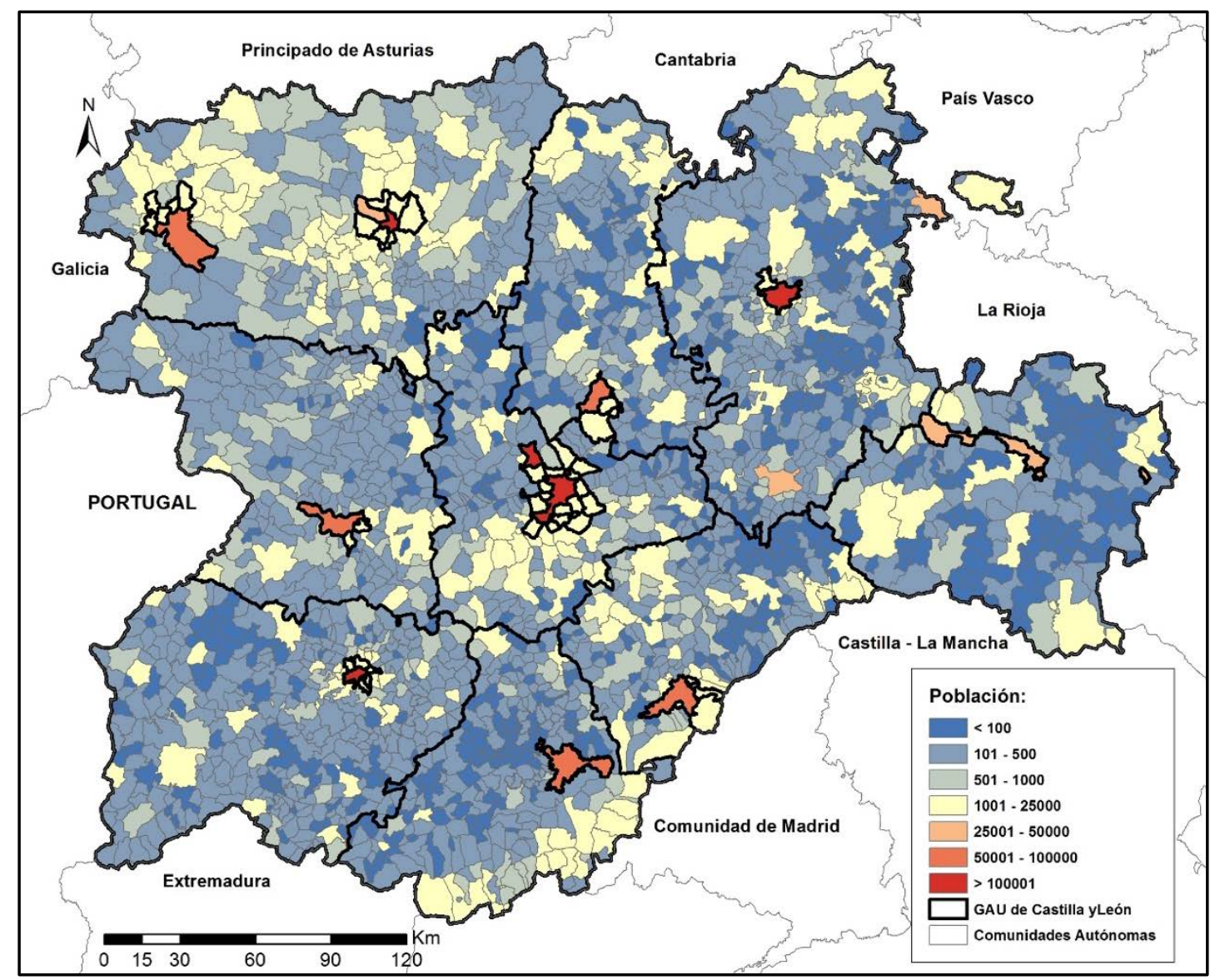

Fuente: elaboración propia a partir de Junta de Castilla y León e INE (2018)

La distribución interprovincial es desigual, aun así se observa una mayoría de territorios escasamente poblados, junto a municipios de cierta relevancia poblacional alrededor de las capitales y sus áreas metropolitanas.

Los municipios mayores de 100000 personas son Burgos, León, Salamanca y Valladolid, que se corresponden con las respectivas capitales provinciales, mientras que las capitales de Ávila, Palencia, Segovia y Zamora, presentan un menor tamaño, entre 50000 y 100000 habitantes, y, finalmente Soria sería la excepción ya que con sus 39112 habitantes (Padrón Municipal de Habitantes a 1 de enero de 2018) no tendría suficiente población para ser considerada como una gran Área Urbana (unimunicipal), pero ejerce como tal en su provincia y en la comunidad a la que pertenece. Todas ellas incluida la ciudad de Ponferrada están consideradas como grandes Áreas 
Urbanas, aunque con una dinámica demográfica baja, pero positiva. Los criterios establecidos por el Ministerio de Fomento son: tener más de 50000 habitantes, y en este caso casi todas ellas tienen suficiente población para que puedan ser tratadas como tales, y además, ejercer su influencia dentro de la red urbana de la comunidad y de la provincia. Los municipios a incluir en las Áreas Urbanas plurimunicipales tendrán como mínimo 1000 habitantes y por último, las denominaciones de las Áreas Urbanas se establecen en función de la ciudad o ciudades principales (Ministerio de Fomento, 2018, p. 20).

En definitiva, estas cifras muestran un espacio poco poblado sobre el que se generan importantes desequilibrios sociales y económicos, siendo una de las características de esta región que continúa presente en la actualidad, y que, según la tendencia de los últimos años y las proyecciones futuras, todo indica que seguirá intensificándose con el paso del tiempo. Por este motivo, es necesario actuar sobre estos pequeños municipios para intentar revertir la dinámica demográfica actual y que les permita mantenerse. Es aquí donde el turismo del vino representa un papel destacado.

\subsection{Metodología y objetivos}

El interés por el enoturismo es cada vez mayor, tanto en el ámbito científico como en el profesional. La aparición de trabajos de investigación ha ido parejo al desarrollo y a la expansión de este tipo de turismo en el medio rural con significativas repercusiones en la economía, en la sociedad, en la cultura y en el patrimonio territorial. Todo ello conlleva a plantear tres objetivos principales a diferentes escalas:

- Analizar la evolución del número de visitantes a bodegas y museos del vino en el conjunto de las Rutas del Vino españolas ¿Cuál es la tendencia global de todas ellas?

- Valorar el papel de las Rutas del Vino de Castilla y León dentro del conjunto nacional. ¿Es Castilla y León un referente enoturístico en España?

- Identificar y caracterizar las distintas Rutas del Vino en Castilla y León, ¿̇es el enoturismo una actividad homogénea en el espacio, o por el contrario existen diferencias territoriales?

Para poder dar respuesta a estas cuestiones se ha utilizado información de diversas fuentes. Las referencias bibliográficas en esta materia son cada vez más ricas y variadas haciendo alusión a estudios teóricos, descriptivos y de casos en España y en otras comarcas vitivinícolas del planeta, lo que refleja el papel tan relevante que tiene este sector económico en el desarrollo del territorio. 
Sin embargo, las empleadas para el desarrollo de la investigación proceden de la página web oficial de Rutas de Vino de España. ${ }^{8}$ Dentro de ella han sido muy valiosos los informes llamados Análisis de Bodegas Rutas del Vino elaborados desde 2008 hasta 2017 que realiza el Observatorio Turístico Rutas del Vino de España. Proporcionan información sobre los servicios enoturísticos que se ofrecen, la tipología de los socios, el impacto económico de las visitas y el número de visitantes en bodegas y museos del vino que se encuentran adheridos al Club del producto "Rutas del Vino de España" (RVE). A través de este último dato se ha podido reconstruir la evolución del número de visitantes que han tenido este tipo de establecimientos vinculados directamente con el enoturismo. ${ }^{9}$ Con ellos se ha conseguido establecer la situación general, de gran utilidad para ver cómo ha evolucionado el sector y, posteriormente, ha permitido realizar comparaciones entre las distintas Rutas del Vino nacionales. Estos informes proporcionan valiosa información complementaria que contribuye al conocimiento en profundidad de la dinámica del sector, como por ejemplo, el precio y gasto medio de la visita, o la distribución de los visitantes por meses, clave para conocer la existencia o no de la estacionalidad de esta actividad y sus repercusiones en el territorio.

Otra fuente empleada en este estudio han sido las páginas web de las Rutas del Vino de Castilla y León, y las entrevistas realizadas a algunos de sus gerentes. Esta información ha sido importante para poder ver el panorama existente en esta región. Con los datos facilitados se ha elaborado una base de datos donde están presentes un total de 157 municipios de la región, junto a la ruta a la que pertenecen, y que tienen como socio al menos a una entidad, pública o privada. Acto seguido se han establecido quince tipologías de socios que engloban a todas las administraciones y empresas presentes, a lo que hay que añadir el total de socios por municipios y por tipo (Tabla 1).

La fuente empleada para la obtención de la cartografía, de las delimitaciones vectoriales de las provincias y de los municipios, ha sido el Instituto Geográfico de Castilla y León ${ }^{10}$ (Infraestructura de Datos Espaciales de Castilla y León- IDECYL). Las delimitaciones de las Grandes Áreas Urbanas

8 Ver www.wineroutesofspain.com

9 Hay que comentar que las cifras de estos informes hacen referencia solo a los establecimientos que son socios de las Rutas del Vino, no a todas las bodegas y museos del vino existentes en España, por lo que las cifras de personas que realizan enoturismo va a ser más elevada.

10 Infraestructuras de Datos Espaciales de Castilla y León. Retrieved from https://cartografia.jcyl.es/web/jcyl/Cartografia/es/Plantilla100/1200034565424/_/_ _ 
han sido descargadas del Ministerio de Fomento, del Atlas Digital de las Áreas Urbanas de España. $^{11}$

Para visualizar mejor la información presentada en este trabajo se ha empleado el software ArcGis (ArcMap) versión 10.2 para elaborar la cartografía. Se han generado mapas de coropletas, que permiten representar fenómenos zonales con valores absolutos o relativos, los intervalos han sido definidos manualmente para así mostrar mejor las semejanzas/diferencias entre los municipios de Castilla y León. Las paletas de colores empleadas en los mapas permiten identificar los contrastes y las igualdades existentes entre ellos. Para el caso de los gráficos y tablas se ha utilizado el programa de hoja de cálculo Excel.

Tabla 1. Tipología de socios por municipio

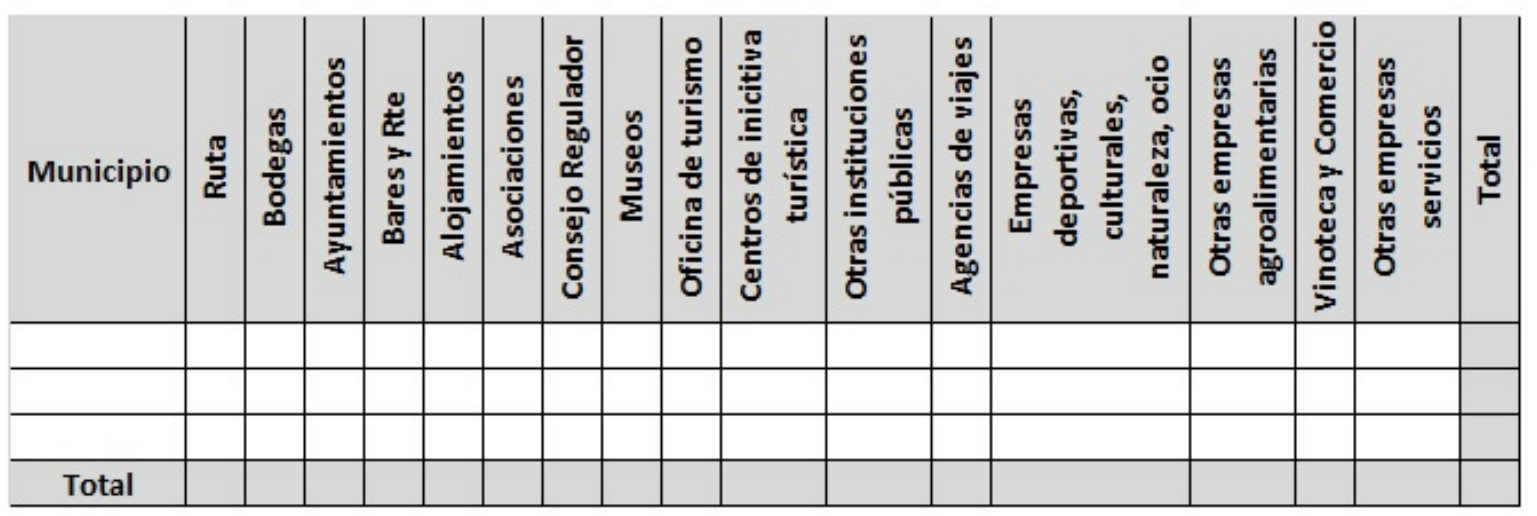

Fuente: elaboración propia a partir de Rutas del Vino de Castilla y León

Los datos demográficos proceden de la página web de la Consejería de Economía y Hacienda, Dirección General de Presupuestos y Estadística de la Junta de Castilla y León ${ }^{12}$ y del Instituto Nacional de Estadística (INE), en concreto del Padrón Municipal de Habitantes 1 de enero del 2018.

\section{Resultados}

\subsection{El crecimiento de los visitantes en las Rutas del Vino de España: del desequilibrio territorial a un turismo del vino más equilibrado}

El interés por el mundo de vino se encuentra en un proceso de continuo ascenso, y prueba de ello es el incremento en la práctica de actividades vinculadas con el enoturismo, en especial, las

11 Atlas Estadísticas de las Áreas Urbanas. Ministerio de Transportes, Movilidad y Agenda Urbana. Retrieved from https://www.fomento.gob.es/portal-del-suelo-y-politicas-urbanas/atlas-estadistico-de-las-areas-urbanas

12 Estadística de Castilla y León. Retrieved from https://estadistica.jcyl.es/ 
visitas a las bodegas y a los museos del vino. Según los datos recogidos en los Informes de visitantes a bodegas y museos del vino asociados a las rutas del vino, el número total de visitantes en el conjunto de estas rutas en España ha experimentado un continuo crecimiento desde 2008 hasta $2017^{13}$ pasando de los 1203269 visitantes a los 3213267 respectivamente, es decir, un crecimiento de un $167 \%$ en diez años (Figura 5). ${ }^{14}$ Todo parece indicar que seguirá incrementándose con el paso de los años por tres motivos principalmente: por el ya comentado interés en esta tipología turística por parte de la población, el aumento de socios en las rutas existentes, y por la aparición de nuevas Rutas del Vino ${ }^{15}$.

\section{Figura 5. Evolución del número de visitantes} en el conjunto de las Rutas del Vino de España 2008-2017

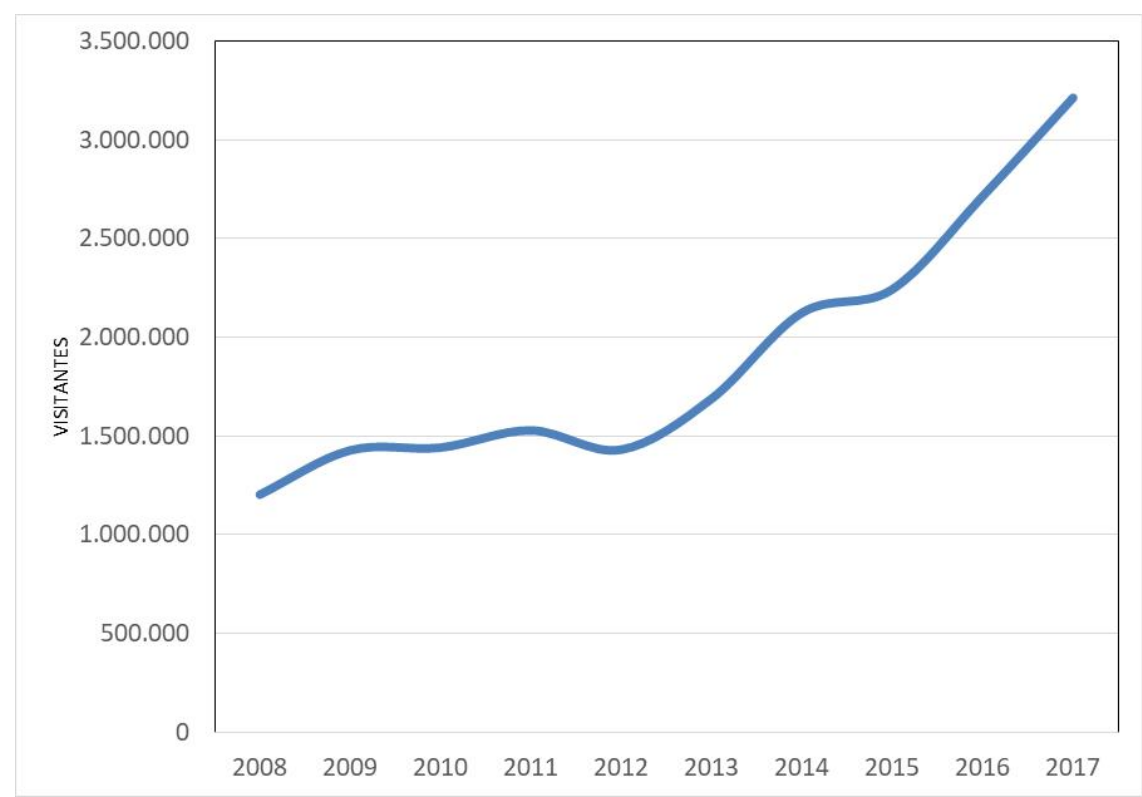

Fuente: elaboración propia a partir de los Informes Análisis de Bodegas Rutas del Vino (2008--2017)

En el periodo de crecimiento se observan dos fases bien diferenciadas. La primera de ellas comprende los años que van desde 2008-2011, momento en el que se comienzan a elaborar

13 En el gráfico se ve un pequeño retroceso entre el 2011 y el 2012 motivado por la falta de datos del año 2012 de algunas rutas como La Rioja Alta, Alicante, Condado de Huelva y Tenerife que han hecho que parezca que haya tenido lugar un descenso. Todo parece indicar que no hubo retroceso sino que el número de visitantes se mantuvo estable.

14 Primeros y últimos datos disponibles. Informes Análisis de Bodegas Rutas del Vino.

15 Recientemente se han añadido dos nuevas Rutas del Vino a esta red. En octubre de 2018 se incorpora de nuevo la Ruta del Vino de La Mancha y en febrero de 2019 la Ruta del Vino de Toro, por lo que la red aumenta año tras año. 
estas estadísticas y con un menor número de rutas certificadas, se pasa de 13 a 21 rutas respectivamente. Este periodo se caracteriza por la estabilidad en el sector. Son años de seguimiento del programa Rutas del Vino y, poco a poco, de su consolidación. El número de socios (bodegas y museos del vino) era más reducido, por lo que las estadísticas recogen datos de un número menor de socios. Aun así, es un indicador que dejaba entrever el valor tan representativo que estaba teniendo esta variedad de turismo, y ya se vislumbraba el papel que iba a tener en el futuro. Una actividad caracterizada por una fuerte presencia en el medio rural, lo que ha supuesto un acicate para espacios de reducida población que han visto cómo se ponían en marcha proyectos para revitalizar la economía en un territorio cada vez más deprimido, en decadencia y en ocasiones casi abandonado.

El segundo periodo, de fuerte crecimiento, comienza a materializarse a partir del año 2012 y se mantiene en la actualidad. La causa más significativa, junto con el interés de la población, se debe al incremento en el número de Rutas del Vino. En el año 2017 había 28, ${ }^{16}$ las cuales aportaban un mayor número de socios, con mayor presencia de bodegas y museos del vino y, por lo tanto, las estadísticas recogen visitantes de un conjunto de establecimientos más amplio dando lugar a cifras más elevadas.

El número de visitantes presenta importantes desequilibrios, pues algunas de estas rutas tienen cientos de miles de visitantes, frente a otras que no llegan a una decena de miles. Las tres rutas más visitadas en el año 2008 eran la Ruta del Vino de Penedés, Jerez y Rioja Alavesa. Entre las tres concentraban el 80,84\% de los visitantes, cifra que refleja la clara polarización del enoturismo en una serie de comarcas vitivinícolas con un fuerte componente histórico de este cultivo, con denominaciones de origen reconocidas internacionalmente, con un rico patrimonio históricoartístico, así como la existencia de los equipamientos necesarios para dar servicio a los visitantes como son alojamientos y restaurantes. Seguidas a estos espacios se encontraban Utiel-Requena, Somontano y Ribera del Duero, con 130661 visitantes de forma conjunta, y cuyas comarcas vitivinícolas presentan las mismas características que las anteriores. Si se suman a las tres primeras concentran el 91,70\% del total con 1103406 visitantes. $^{17}$

La situación en 2017 (Tabla 2) es algo diversa a la de 2008. Si bien, a pesar de seguir existiendo una considerable concentración en una serie de territorios, los porcentajes son inferiores. Las seis

16 En el 2018 eran 29 y en el 2019 ya son 30.

17 Visitantes en el año 2008: Penedés 457 896, Jerez 434 161, Rioja Alavesa 80688 , Utiel-Requena 47496 , Somontano 46099 y Ribera del Duero 37 066. Fuente: Informe Análisis de Bodegas Rutas del Vino 2008. 
primeras rutas del vino este año fueron las de Jerez, Penedés, Ribera del Duero, Empordá, Calatayud y Rioja Alta ${ }^{18}$ con el 72,11\% del total de visitantes que recorrieron alguna de las bodegas y museos del vino inscritos en ellas, casi un 20\% menos de lo que suponían las seis rutas más visitadas en el 2008. Sin embargo, en cifras absolutas crecen hasta 2317062 visitantes, es decir, 1213656 nuevos visitantes. Estos datos reflejan la expansión del resto de rutas, pues van adquiriendo cada vez más peso en el cómputo final. Es verdad que las grandes rutas crecen, pero también lo hace el resto, y por este motivo pierden representatividad porcentual aunque la mayoría ganan en cifras absolutas.

El éxito del fenómeno Rutas del Vino se encuentra en lo relativo a la gestión y planificación de los recursos turísticos, lo que ha conseguido despertar el interés en empresarios y administraciones locales por pertenecer a este ente. La red va siendo cada vez más amplia, se está tejiendo una malla que abarca cada vez más territorios, con más socios, con servicios más diversificados, y por ende, es capaz de llegar a un público cada vez mayor y variado.

18 Visitantes en el año 2017: Jerez 574 242, Penedés 438 112, Ribera del Duero 378 663, Empordá 373 206, Calatayud 296597 y Roja Alta 256 303. Fuente: Informes Análisis de Bodegas Rutas del Vino 2017. 
Tabla 2. Rutas del Vino en España por Comunidades Autónomas

\begin{tabular}{|c|c|c|c|c|c|}
\hline Comunidad Autónoma & Nombre ruta & $\begin{array}{l}\text { Total rutas por } \\
\text { Comunidad } \\
\text { Autónoma }\end{array}$ & $\begin{array}{l}\text { Visitantes } \\
\text { totales } 2017\end{array}$ & $\begin{array}{l}\text { \% respecto } \\
\text { al total de } \\
\text { visitantes }\end{array}$ & $\begin{array}{l}\text { Incremento desde } \\
\text { su certificación } \\
\text { hasta } 2017^{19}\end{array}$ \\
\hline \multirow{9}{*}{ Castilla y León } & Bierzo & & 27027 & 0,84 & 16898 \\
\hline & Sierra de Salamanca & & 1388 & 0,04 & - \\
\hline & Cigales & & 13990 & 0,44 & 9059 \\
\hline & Rueda & & 32372 & 1,01 & 11932 \\
\hline & Ribera del Duero & & 378663 & 11,78 & 341597 \\
\hline & Arlanza & & 16028 & 0,50 & - \\
\hline & Arribes & & - & - & - \\
\hline & Toro & & - & - & - \\
\hline & Total Castilla y León & 8 & 469468 & 14,61 & 379486 \\
\hline \multirow{2}{*}{ Galicia } & Rías Baixas & & 115459 & 3,59 & 108448 \\
\hline & Total Galicia & 1 & 115459 & 3,59 & 108448 \\
\hline \multirow{3}{*}{ País Vasco } & Rioja Alavesa & & 169888 & 5,29 & 89200 \\
\hline & Txacolí & & 4093 & 0,13 & -542 \\
\hline & Total País Vasco & 2 & 173981 & 5,41 & 88658 \\
\hline \multirow{3}{*}{ La Rioja } & Rioja Alta & & 256303 & 7,98 & 185545 \\
\hline & Rioja Oriental & & - & - & - \\
\hline & Total La Rioja & 2 & 256303 & 7,98 & 185545 \\
\hline \multirow{2}{*}{ Navarra } & Navarra & & 29444 & 0,92 & 17076 \\
\hline & Total Navarra & 1 & 29444 & 0,92 & 17076 \\
\hline \multirow{5}{*}{ Aragón } & Somontano & & 77541 & 2,41 & 31442 \\
\hline & Calatayud & & 296597 & 9,23 & 45202 \\
\hline & Campo de Borja - Garnacha & & 56645 & 1,76 & 55200 \\
\hline & Campo de Cariñena & & 20636 & 0,64 & 3359 \\
\hline & Total Aragón & 4 & 451419 & 14,05 & 135203 \\
\hline \multirow{4}{*}{ Cataluña } & Lleida & & 52116 & 1,62 & 29988 \\
\hline & Empordá & & 373206 & 11,61 & 336006 \\
\hline & Penedés & & 438112 & 13,63 & -19784 \\
\hline & Total Cataluña & 3 & 863434 & 26,87 & 346210 \\
\hline \multirow{3}{*}{ C. Valenciana } & Utiel-Requena & & 71295 & 2,22 & 23799 \\
\hline & Alicante & & 41662 & 1,30 & 27901 \\
\hline & Total C. Valenciana & 2 & 112957 & 3,52 & 27901 \\
\hline \multirow{4}{*}{ Murcia } & Yecla & & 5537 & 0,17 & 3911 \\
\hline & Jumillas & & 36773 & 1,14 & 26045 \\
\hline & Bullas & & 21612 & 0,67 & 21001 \\
\hline & Total Murcia & 3 & 63922 & 1,99 & 50957 \\
\hline \multirow{4}{*}{ Andalucía } & Montilla-Moriles & & 17249 & 0,54 & 4906 \\
\hline & Marco de Jerez & & 574242 & 17,87 & 140081 \\
\hline & Serranía de Ronda & & 38686 & 1,20 & 28503 \\
\hline & Total Andalucía & 3 & 630177 & 19,61 & 173490 \\
\hline \multirow{2}{*}{ Extremadura } & Ribera del Guadiana & & 46704 & 1,45 & 23222 \\
\hline & Total Extremadura & 1 & 46704 & 1,45 & 23222 \\
\hline \multirow{2}{*}{ Castilla La Mancha } & La Mancha & & - & - & - \\
\hline & Total Castilla La Mancha & 1 & - & - & - \\
\hline \multicolumn{2}{|c|}{ Total Rutas } & 30 & 3213268 & 100 & 1536196 \\
\hline
\end{tabular}

Fuente: elaboración propia a partir de los Informes Análisis de Bodegas Rutas del Vino (2008--2017)

\subsection{El papel de las Rutas del Vino de Castilla y León dentro del conjunto español}

Al igual que sucede con el número de visitantes, y como ya se ha avanzado, existe cierto desequilibrio en lo que respecta a la distribución espacial de las Rutas del Vino por el territorio. 
No todas las comunidades cuentan con ruta del vino, a pesar de que todas ellas, en menor o mayor medida, poseen superficie de viñedo y elaboran un tipo u otro de vino, la mayoría dentro de un espacio productor de calidad. Quedan fuera Cantabria y el Principado de Asturias por su carácter montañoso, por su amplia superficie dedicada al pasto, y por el desarrollo de otro tipo de productos, en el caso de Asturias la sidra, que cuenta ya con reconocimiento previo y una menor competencia que el vino. Tampoco poseen rutas ninguno de los dos archipiélagos, el canario y el balear, a pesar de tener viñedos significativos como los de La Geria en Lanzarote (González Morales, Ramón Ojeda \& Hernández Torres, 2015) o los de la isla de Mallorca (Binimelis Sebastian, 2019) ya que apuestan de forma contundente por el desarrollo del turismo de sol y playa, y tampoco la Comunidad de Madrid que se centra en un turismo cultural de carácter urbano. En el resto existe al menos una Ruta del Vino que se encarga de promocionar el territorio constituyéndose como un elemento vertebrador, a partir del cual, se configura un producto turístico capaz de integrar la diversidad de la oferta existente en su entorno.

En total existen treinta Rutas del Vino, la mayoría de ellas coinciden con comarcas vitivinícolas. Veinte se encuentran en la mitad norte peninsular, frente a las diez restantes que están en la mitad sur (Figura 6). Los motivos que explican esta distribución son varios aunque destacan el peso que posee el turismo de interior y, especialmente en Castilla y León, la primera región en la recepción de visitantes y pernoctaciones en el año 2018 con casi un $20 \%$ del total español, ${ }^{20}$ casi el doble que la segunda comunidad autónoma en esta clasificación, Cataluña con 11,45 \%, lo que revela el papel tan representativo de este tipo de turismo en la economía rural castellanoleonesa. Estas cifras permiten entender el hecho de que una parte considerable de la inversión se centre en el desarrollo de esta tipología turística, pues es un recurso en alza, muy atractivo, y que consigue aprovechar los recursos del territorio, frente a las regiones del sur y del sureste que se encuentran más enfocadas a un turismo de sol y playa.

Junto a ello hay que añadir que en el norte peninsular se encuentran numerosas comarcas vitivinícolas reconocidas, nacional e internacionalmente, como son Rioja, Penedés, Ribera del Duero, Rías Baixas o Cariñena entre otras que despiertan mayor interés debido a su peso histórico en el cultivo de la vid y su posterior transformación en vinos que además cuentan con mención de calidad. Prueba de ello es que, de las diez Rutas del Vino con más visitantes en 2017, ocho de

20 Encuesta de ocupación en alojamientos de turismo rural del Instituto Nacional de Estadística para el año 2018. En el conjunto de España, en el 2018, el total de viajeros y pernoctaciones fue de 4250874 , de los cuales 818 789 correspondían a Castilla y León y 487015 a Cataluña. 
ellas se encontraban en la mitad norte ${ }^{21}$ con un total de 2105769 visitantes frente a dos que estaban en la mitad sur ${ }^{22}$ con 645537 visitantes. De todas ellas, es la Ruta del Vino Ribera del Duero en Castilla y León la que ha tenido el mayor crecimiento en números absolutos, y es, además, la ruta con el gasto medio por visitante más elevado con 40,54€ seguido de la Rioja Alavesa con $29,44 €,{ }^{23}$ lo que repercute directamente en la economía local al ser dinero que se dirige a las bodegas, bares, restaurante, tiendas, etc.

\section{Figura 6. Croquis de la localización de las Rutas del Vino de España}

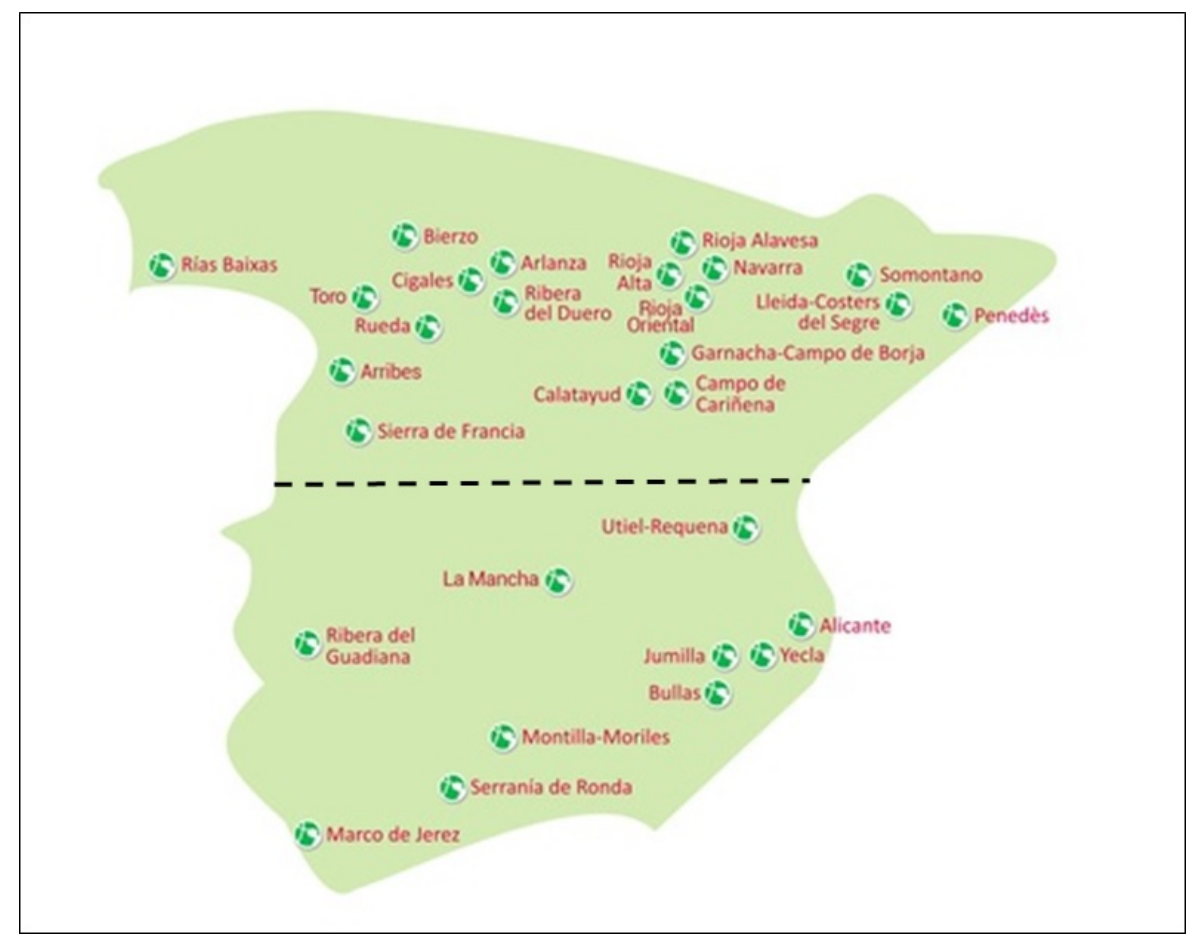

Fuente: Rutas del Vino de España ACEVIN

Algo más de una cuarta parte del total de las Rutas del Vino se localizan en Castilla y León, en concreto ocho, la región con mayor número en España, aunque es la tercera en número de visitantes por detrás de Cataluña y de Andalucía con tres rutas cada una. Si bien, es cierto, que en el caso de Castilla y León, seis de estas rutas han sido certificadas por ACEVIN hace apenas unos años y se encuentran en proceso de consolidación y expansión. Esta fase consiste en explicar el proyecto a futuros socios, a los ayuntamientos, a los empresarios de la zona y a los ciudadanos

21 Las ocho rutas, de mayor a menor número de visitantes, son: Penedés, Ribera del Duero, Empordá, Calatayud, Rioja Alta, Rioja Alavesa, Rías Baixas y Somontano.

22 Las dos rutas, de mayor a menor número de visitantes, son: Jerez y Utiel-Requena.

23 Datos del Informe de visitantes a bodegas y museos del vino asociados a las Rutas del Vino de España en el año 2017. No se tiene en cuenta el alojamiento. 
principalmente, con el objetivo de dar a conocer el trabajo que realizan y captar nuevos socios. La Ruta del Vino de Rueda, certificada en 2013, y la Ruta del Vino Cigales, en 2015, ya se encuentran, más o menos consolidadas y poseen una dinámica de crecimiento que se observa año tras año, al igual que sucede con la Ruta del Vino del Bierzo creada en el año 2011. Respecto a las rutas de Arlanza y Sierra de Francia, certificadas en 2017, la de Arribes en 2018 y Toro en 2019, es pronto para ver su comportamiento, aunque todo parece indicar, al igual que ha ocurrido con las rutas precedentes, que en los próximos años se consoliden y aporten cifras importantes al cómputo global de la región incrementando la representatividad de visitantes en el total nacional.

Estas cifras reflejan la apuesta de esta región por el enoturismo como un motor de desarrollo económico del medio rural, pues todas ellas abarcan un total de 157 municipios $^{24}$. La mayoría de ellos son pequeños, muchos con menos de 500 habitantes, a excepción de algunos núcleos que funcionan como cabecera de las mismas y que cuentan con un volumen de población mayor como son Medina del Campo, Ponferrada, Aranda de Duero, Peñafiel, Cigales o Lerma. En estos casos, estas entidades tienden a aglutinar una considerable oferta de servicios y actividades, y por consiguiente, un mayor número de socios.

\subsection{El enoturismo en Castilla y León: una actividad en expansión que vertebra el territorio}

Que el enoturismo es un referente socioeconómico para Castilla y León es evidente, además de un foco de empleo necesario para el mantenimiento de determinadas áreas rurales. La tendencia entre 2008 y 2017 ha sido ascendente (Figura 7), a excepción de un pequeño retroceso entre los años 2009-2010, cuando solo se consideraban los visitantes de la única Ruta del Vino existente, la de Ribera del Duero, y la variabilidad podía ser mayor ante cualquier coyuntura, en especial ante un pequeño descenso en el número de bodegas asociadas a la ruta, y por ello, menos visitantes registrados. Pero desde entonces, la evolución ha sido positiva. El motivo de la fuerte expansión se debe a la amplia red de Rutas del Vino que se han ido adhesionando a lo largo de los años y que han sumado cada vez más visitantes. En diez años, se ha pasado de poco más de 37000 visitantes a 469 468, es decir, se ha multiplicado por 12,66 puntos la cifra de partida, y todo parece indicar que esta dinámica alcista se mantendrá en los próximos años cuando se acaben de desarrollar las rutas incorporadas recientemente, reforzando el papel de Castilla y León en este sector económico como un referente a escala nacional.

24 Para el estudio no se han tenido en cuenta los datos de la Ruta del Vino Toro, cuya certificación ha sido aprobada por ACEVIN en febrero de 2019 y no disponemos de datos, por lo que no se incluye en el trabajo. 
Figura 7. Evolución del número de visitantes en el conjunto de las Rutas del Vino de Castilla y León 2008-2017

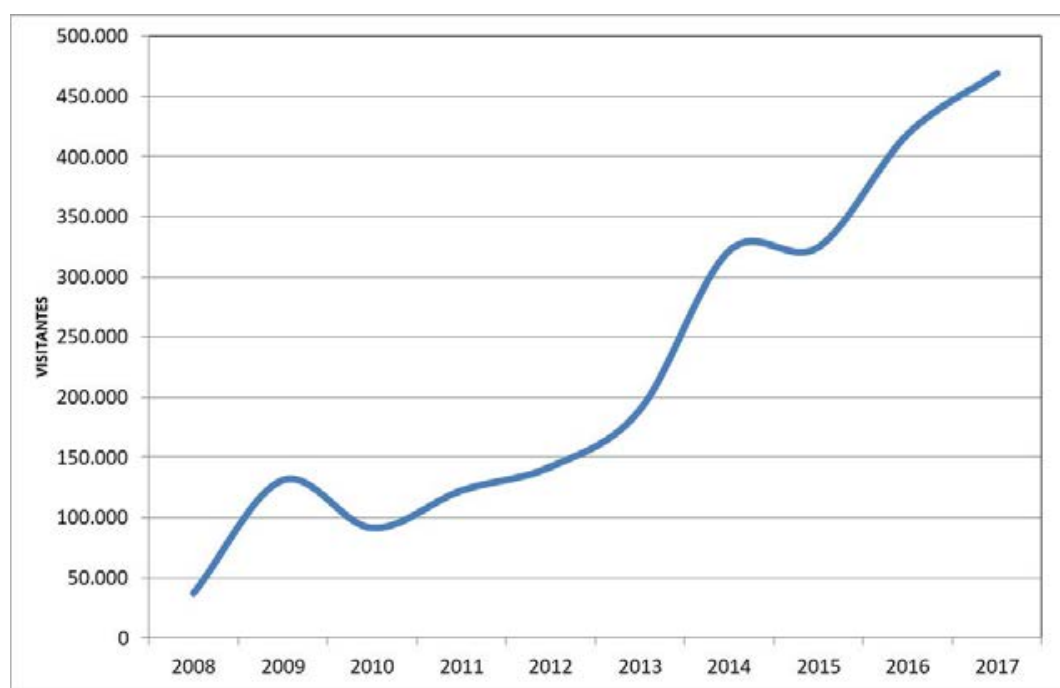

Fuente: elaboración propia a partir de los Informes Análisis de Bodegas Rutas del Vino (2008--2017)

Tabla 3. Visitantes en las Rutas del Vino de Castilla y León en 2017

\begin{tabular}{|l|c|r|}
\hline \multicolumn{1}{|c|}{ Ruta del Vino } & Visitantes & Porcentaje \\
\hline Ribera del Duero & 378.663 & 80,66 \\
\hline Rueda & 32.372 & 6,90 \\
\hline Bierzo & 27.027 & 5,76 \\
\hline Arlanza & 16.028 & 3,41 \\
\hline Cigales & 13.990 & 2,98 \\
\hline Sierra de Salamanca & 1.388 & 0,30 \\
\hline Arribes* & - & - \\
\hline Toro** & & 100,00 \\
\hline \multicolumn{2}{|c|}{ Total } & 469.468 \\
\hline
\end{tabular}

* La Ruta del Vino Arribes surge en el año 2018 y no hay datos disponibles.

** La Ruta del Vino Toro surge en febrero del año 2019 y no hay datos disponibles.

Fuente: elaboración propia a partir de los Informes Análisis de Bodegas Rutas del Vino (2008--2017)

A pesar de estas cifras tan positivas, la dicotomía territorial es significativa, pues el $80 \%$ de los visitantes de 2017 llegaron a la Ruta del Vino Ribera del Duero, frente al restante 20\% que sumaban las otras cinco rutas que contaban con datos (Tabla 3). La Ribera del Duero es un espacio que ha conseguido crear una marca territorial que se encuentra consolidada y arraigada entre sus 
moradores, así como en el exterior. El complejo vitivinícola bodega-viñedo-enoturismo está consiguiendo que algunas de las pequeñas poblaciones, tan características de este espacio y que estaban condenadas al abandono, estén desarrollando propuestas de revitalización y diversificación económica del territorio con la creación de bodegas y de empresas auxiliares vitivinícolas, así como la expansión de un sector servicios con un fuerte anclaje rural.

Sin embargo, esta dualidad entre Ribera del Duero y el resto de Rutas del Vino, lejos de ser un inconveniente, contribuye a ensalzar la imagen vitivinícola de la región y de los territorios que lo conforman. A pesar del fuerte crecimiento de esta comarca productora, ha ido perdiendo importancia porcentual respecto al conjunto regional, pues al igual que lo ocurrido en el caso español, la aparición de otras Rutas del Vino desde el 2011 y hasta la actualidad ha hecho posible la existencia de una oferta más amplia incorporando nuevos visitantes a diferentes territorios. Lo más probable es que este peso de Ribera del Duero siga disminuyendo a medida que el resto de rutas consigan consolidarse como destinos enoturísticos. En 2008 el 100 \% de los visitantes iban a la Ribera del Duero, en 2014 era el 89,89 \% y en el 2017 el 80,65 \%. Lo normal es que este valor porcentual disminuya con el crecimiento de las Rutas del Bierzo, Rueda, Cigales y Arlanza, con la expansión de Sierra de Salamanca, y la aparición más reciente de Arribes y Toro.

En su conjunto, estas rutas ${ }^{25}$, agrupan a un total de 721 socios repartidos en 157 municipios (Figura 8). Algunos cuentan con un socio, frente a otros que tienen dos, tres, cuatro o incluso 45 socios. La tercera parte de estos socios y de los municipios en los que se ubican pertenecen a Ribera del Duero. También hay que mencionar que hay otros municipios dentro de estas comarcas vitivinícolas que no poseen ningún establecimiento, organismo o asociación como miembros de las Rutas del Vino.

En Castilla y León se pueden diferenciar las Rutas del Vino que están expandidas por toda o casi toda la comarca vitivinícola como son Cigales, ${ }^{26}$ Sierra de Salamanca, Bierzo y Ribera del Duero, frente a las otras que aglutinan, en menos municipios, un mayor número de socios como por ejemplo Arribes, Arlanza o Rueda, ${ }^{27}$ lo que da como resultado un espacio más vacío, desestructurado y carente de actividades enoturísticas con lo que esto conlleva para el medio rural.

25 Hay que recordar, como ya se ha comentado, que la Ruta del Vino de Toro no entra dentro de este estudio al ser de reciente creación y no disponer de datos para el estudio.

26 En los doce municipios que componen la DO Cigales hay al menos un socio en cada uno de ellos.

27 De los setenta y dos municipios que componen la DO Rueda, hay socios de la Ruta del Vino en diecinueve de ellos. 
Respecto a la tipología de socios existente es variada. Los más destacados son las bodegas (con 143 socios, representan un $20 \%$ sobre el total de los socios), luego los alojamientos con un total de 122 socios (16,9\%), en los que se aprecia una amplia casuística ya que pueden ser desde hoteles de diferentes categorías, hostales, posadas o alojamientos rurales, hasta campings. Finalmente se encuentran los bares y restaurantes (con 100 socios, 16,9\%), muchos de ellos son de nueva creación, al amparo del reclamo de las rutas del vino y otros anteriores a este fenómeno situados en las cercanías de las más importantes vías de comunicación de la Comunidad, muy conocidos por su buena cocina. También hay que mencionar el papel de los museos del vino (31) y que junto con los socios mencionados anteriormente son los pilares en los que se apoya el turismo del vino.

Figura 8. Distribución municipal del total de Socios

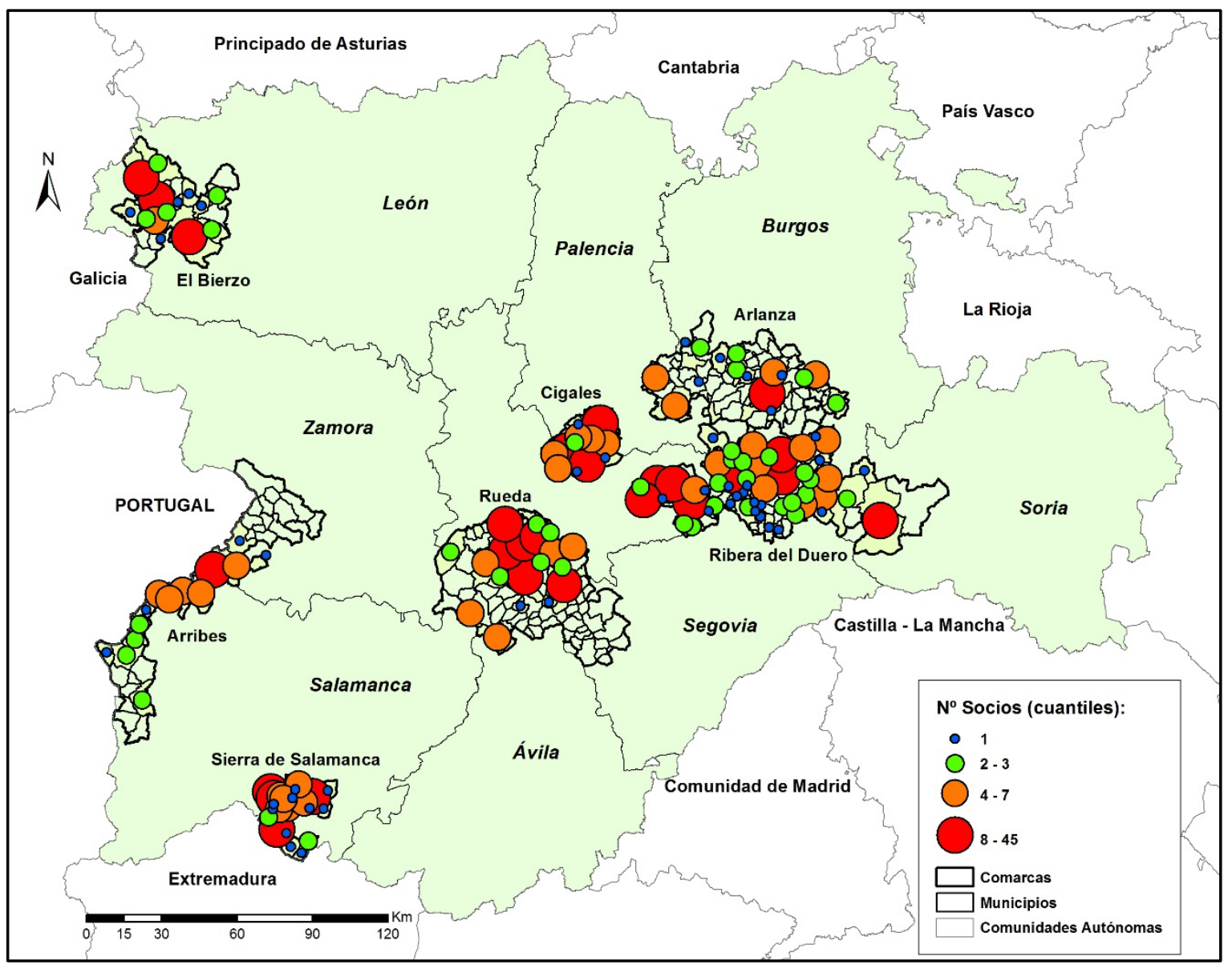

Fuente: Informe Análisis de Bodegas Rutas del Vino 2017. Elaboración propia.

Por comarcas (Figura 9) y teniendo en cuenta los tres tipos de socios más frecuentes citados en el párrafo anterior, las Rutas del Vino presentan un porcentaje de socios "bodegas" de entorno al 40\%, a excepción de Sierra de Salamanca que cuenta con tan solo 6 socios dentro de este grupo y representa el 13,3\%, y que se debe al menor número de bodegas existentes en la DO Sierra de 
Salamanca. En las demás comarcas el porcentaje de socios "bares y restaurantes" y de "alojamientos" concentra alrededor del $60 \%$, unas cifras que varían un poco entre unas DO y otras. Por ejemplo, en la comarca de Ribera del Duero el porcentaje es más elevado en socios de alojamientos que en el de bares y restaurantes, en Cigales sucede lo contrario, mientras que en Rueda casi tienen el mismo valor porcentual los dos tipos de socios.

Figura 9. Distribución comarcal de los principales tipos de socios

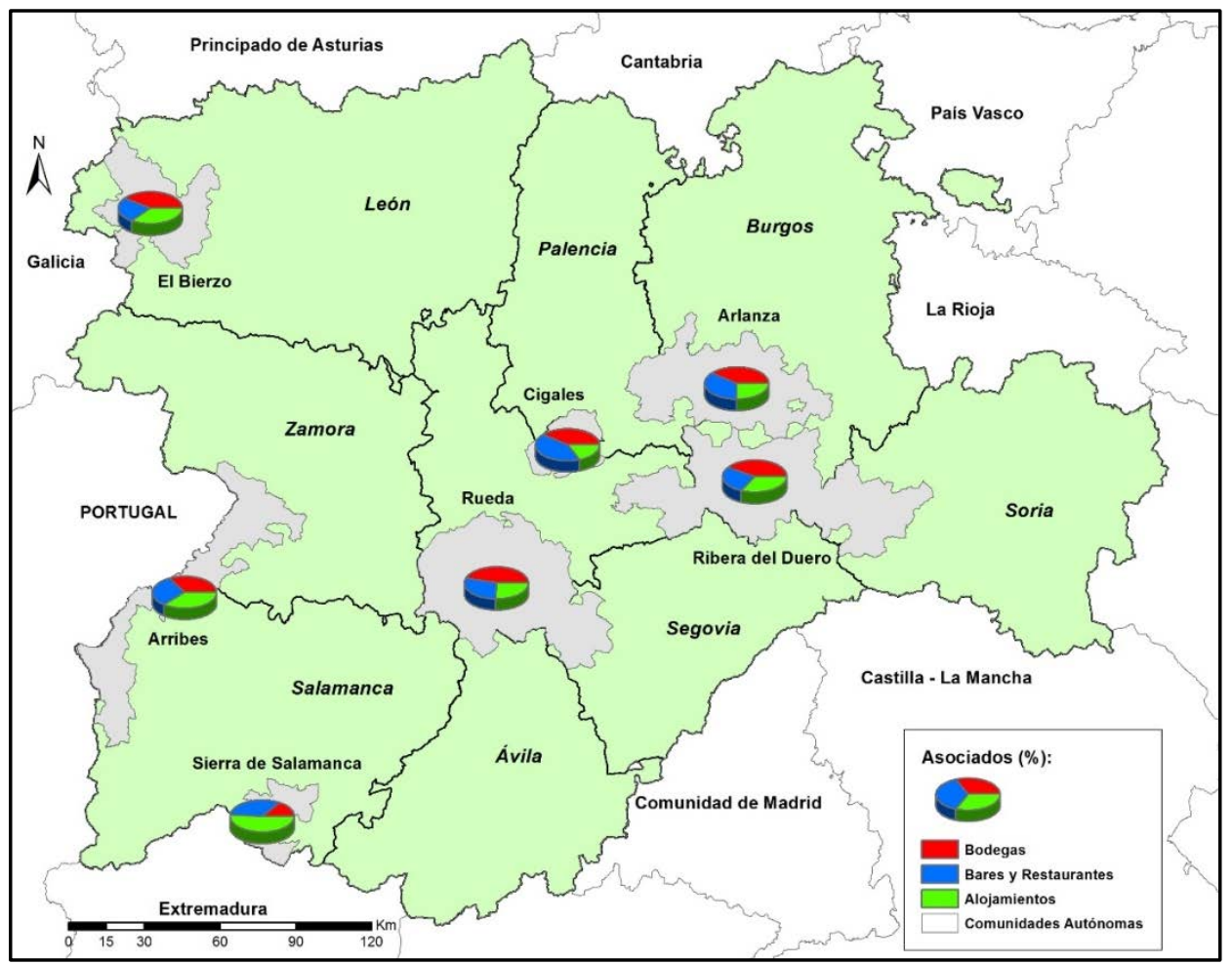

Fuente: elaboración propia a partir de los Informes Análisis de Bodegas Rutas del Vino (2008--2017)

Junto a esta tipología de socios existen otras empresas, de variada actividad, que diversifican y completan la oferta de ocio y entretenimiento, así como empresas que ayudan a la organización del viaje. Entre las más frecuentes destacan:

- Empresas agroalimentarias: carnicerías, queserías, pastelerías, tiendas gourmet, vinotecas, etc.

- Empresas deportivas, de ocio y entretenimiento.

- Otras empresas de servicios: empresas de GIS, ceramistas, fotógrafos, empresas de transporte, guías turísticas, agencias de viajes, etc.

- Asociaciones: Grupos de Acción Local, mancomunidades, asociaciones de patrimonio, etc. 
Todos ellos se consideran servicios necesarios que permiten que los visitantes puedan permanecer uno o más días en el territorio. A ellos hay que añadir el apoyo de las administraciones locales, a través de los ayuntamientos, y que es esencial, pues contribuyen junto con las rutas a la organización y desarrollo de actividades de promoción, difusión, gestión y custodia del territorio rural.

\section{Discusión}

El estudio realizado pretende mostrar la relevancia que adquieren las Rutas del Vino en el conjunto de Castilla y León como una actividad que contribuya a la diversificación económica y al desarrollo rural de los municipios vinculados directamente con el mundo del vino, así como a los de su entorno. Una situación que ya se produce en otros territorios del país, donde la organización de una serie de entidades públicas como son los ayuntamientos, junto con empresas privadas como bodegas, restaurantes, hoteles, etc., y las denominaciones de origen del vino, se unen para ofrecer un producto turístico que tiene como nexo de unión un cultivo, el viñedo, y un producto derivado de la uva, el vino.

El turismo es desde hace años una de estas actividades que contribuye al mantenimiento de la economía de los espacios rurales y al desarrollo endógeno. Son numerosas las iniciativas que existen en el mundo y que tienen como elemento principal para su desarrollo un producto agroalimentario propio de espacios rurales que, además de su uso como alimento, han encontrado en el turismo una nueva forma de rentabilizar un producto. Además de contribuir a la diversificación de la economía del territorio y complementar las rentas de los agricultores, así como de otras personas que han decidido apostar por el medio rural con la creación de empresas turísticas, de ocio y recreación vinculada a estos productos agroalimentarios.

En el caso del enoturismo, el vino de calidad se convierte en el reclamo para visitar un territorio, aunque luego se complemente con otros atractivos como puede ser el patrimonio históricoartístico, la naturaleza, la gastronomía, las fiestas, etc. (Miranda Escolar \& Fernández Morueco, 2011). Una idea que compartimos, pues aunque el vino y su cultura sea el motivo principal del viaje, los turistas no pasan toda su estancia visitando bodegas, sino que aprovechan el resto de recursos que ofrece la comarca vitivinícola a la que acuden.

Las Rutas del Vino, territorialmente, se encuentran asociadas a espacios vitivinícolas. Para poder conformarse como ruta, es necesario el cumplimiento de unos criterios de calidad y de unas normas de autorregulación establecidas por ACEVIN y la Secretaria de Estado de Turismo 
(https://www.wineroutesofspain.com/), estas normas reciben el nombre de Manual del Producto Turístico Rutas del Vino de España. En este documento se establecen los requisitos a cumplir relacionados con el sistema de gestión, la señalización, la promoción y la comercialización del ente de forma global, pero también se establece la normativa que tienen que cumplir los socios que pertenezcan a la ruta como pueden ser las bodegas, bares, restaurantes, vinotecas, etc. Unas exigencias que lo que pretenden, bajo nuestro punto de vista y que son acertadas, es otorgar a los territorios que se conforman como rutas del vino, la calidad, la personalidad, la unicidad, en definitiva, ofrecer algo diverso al resto de espacios que sea capaz de atraer a los visitantes y contribuir al desarrollo del medio rural. Por ello, es necesario establecer unos requisitos mínimos para su configuración, y de esta forma evitar la proliferación de espacios que no aporten nada en especial.

Existen numerosos trabajos que indican que el enoturismo es un factor clave en el desarrollo del medio rural español, y que se ha consolidado como un recurso económico para pequeños municipios (Martínez Puche \& Morales Yago, 2016; Plaza Tabasco, Cañizares Ruiz \& Ruiz Pulpón, 2017). Efectivamente esto es así, pues pequeños municipios, con una economía de base agraria, han podido diversificar su economía hacia la actividad industrial y de los servicios. Dentro del enoturismo hay que incluir los trabajos en los que las Rutas del Vino adquieren un papel relevante dentro de esta tipología turística. Las conclusiones de estos últimos coinciden en afirmar que el turismo enológico, apoyado en gran parte en las Rutas del Vino, contribuye a la dinamización socio-económica del territorio (Cordeiro Gonçalves, 2012). Esta situación ha tenido lugar en la Ruta del Vino de Jerez (Vieira Rodríguez, López-Guzmán \& Rodríguez García, 2012), y en las de Jumillas y Bullas en Murcia (Millán Escriche, 2012), las cuales han sido capaces de generar un efecto de arrastre a otras empresas, no solo a las bodegas, sino también a los establecimientos hosteleros y comerciales. Esta situación la hemos podido observar también en nuestro estudio para el caso de Castilla y León pues han tenido y están teniendo, los mismos efectos que en Jerez, Jumillas y Bulas. Las Rutas del Vino coinciden con denominaciones de origen, y son capaces de dinamizar económica y socialmente las comarcas vitivinícolas.

\section{Conclusiones}

El turismo es uno de los pilares fundamentales en los que se sustenta el desarrollo rural y ha conseguido revitalizar a un conjunto de pequeños municipios españoles gracias al desarrollo de una serie de actividades, muchas de ellas vinculadas directamente con la agroindustria, y que van 
asociadas a la aparición y posterior expansión de empresas de servicios, la mayoría dedicadas al ocio y la recreación de las personas.

El turismo es desde hace años una de estas actividades que contribuye al mantenimiento de la economía en estos espacios. La variedad de actividades que engloban al turismo rural es alta y variada. Dentro del turismo, las vinculadas al vino, el denominado enoturismo o turismo del vino, se encuentran cada vez más arraigadas en el espacio y entre la población y están experimentado un crecimiento cada vez mayor con nuevas alternativas que ayudan al desarrollo rural y a la dinamización del tejido social con la puesta en marcha de estrategias de innovación. Junto a todo el entramado vitivinícola hay que añadir la organización de actividades y la aparición de empresas, no relacionadas directamente con el mundo del vino, pero que contribuyen al fortalecimiento, no solo del enoturismo, sino del turismo rural en general, y por ende, de la economía territorial. Para ello han sido necesarias grandes inversiones por parte de entes públicos y empresas privadas, locales y foráneas, donde las iniciativas financiadas por fondos europeos (PRODER y LEADER) y gestionadas, principalmente, a través de los Grupos de Acción Local, han sido imprescindibles para intentar lograr la cohesión territorial, la revitalización y el mantenimiento de algunas áreas rurales, y contribuir a la custodia del territorio con el desarrollo de actividades de turismo sostenible.

Si bien, es cierto que estas nuevas actividades han conseguido crear nuevos empleos y riqueza en algunos municipios, pero sin embargo, no se ha conseguido mantener la población o el asentamiento de nuevos pobladores como se esperaba. La cercanía y accesibilidad de los pueblos vitivinícolas a las capitales de provincia, áreas metropolitanas o cabeceras comarcales posee ventajas e inconvenientes. Como ventaja más significativa se encuentra la relativa buena conexión de la mayor parte de los municipios de economía vitivinícola a alguno de estos tres territorios. A pesar de todo, esta ventaja se convierte en un inconveniente, pues estos espacios ejercen un poder de atracción tan grande que fagocitan la concentración de todo tipo de actividades, servicios básicos educativos y sanitarios, y con ello de población. Todo ello provoca movimientos pendulares diarios de los municipios urbanos a los rurales permitiendo a las personas trabajar en el medio rural pero vivir en núcleos urbanos o de mayor tamaño.

Mientras los pueblos pierden población y servicios, los ganan algunos, no todos, pues la crisis característica del medio rural se ha trasladado también a las ciudades y entidades de mayor población de Castilla y León, y la situación actual es de "desbandada" de la población joven y de "imparable" envejecimiento de los efectivos demográficos. Todo ello presenta un panorama 
desolador en Castilla y León donde es necesaria la intervención de las administraciones públicas para poner en marcha políticas e iniciativas de ordenación territorial que consigan revertir este proceso antes de que se pierdan generaciones activas, bien formadas y necesarias para el funcionamiento y el desarrollo de la región (González-Leonardo y López-Gay, 2019), así como la desaparición de algunos pueblos, situación que ya está ocurriendo, y evitar las consecuencias que ello conllevaría para la población, la naturaleza, el campo, el patrimonio, en definitiva, para la vida, no solo rural, sino también urbana de esta región.

Una de las iniciativas que mejores resultados está teniendo es el desarrollo del enoturismo. Esta actividad ha supuesto y supone un soplo de vida para el medio rural, por sí sola es insuficiente, es solo una pieza dentro de un complejo puzle en el que se tienen que encontrar los restantes fragmentos para poder encajarlos y conseguir la fórmula adecuada que permita el mantenimiento de la vida en el medio rural. Dentro de este contexto, las Rutas del Vino ejercen un papel clave como ente encargado de gestionar los recursos que posee el territorio con el objetivo de promocionarlo, darlo visibilidad y poniendo en valor todas las potencialidades que ofrece.

Castilla y León lleva años apostando por el desarrollo de una pujante industria vitivinícola de calidad, ensalzando al vino como uno de sus productos más significativos y reconocidos. Asociado a ello está ejerciendo una política activa de promoción del enoturismo como uno de sus pilares claves para la economía rural, pues ocho de las nueve provincias castellanoleonesas, a excepción de la provincia de Ávila, cuentan con al menos una Ruta del Vino en su territorio.

Frente a estos datos hay que hablar de los desequilibrios espaciales existentes dentro de las propias rutas. Por un lado, los municipios con mayor número de socios, capaces de organizar más eventos y actividades y de mayor envergadura, con mayor repercusión en el territorio, y que generalmente cuentan con mayor población, más de 1000 habitantes aunque algunos de ellos superan los 5000 e incluso los 30 000. Como ejemplos se encuentran Aranda de Duero (45 socios), Medina del Campo (32), Peñafiel (31), Rueda (19), Fermoselle (18), Cacabelos (17) o Cigales (16), y que concentran el 41,35\% de los socios en tan solo 18 municipios $(11,46 \%)$ de los 157 que pertenecen a alguna de las rutas. A pesar de que una parte importante se concentra en los municipios más grandes, hay que resaltar que la otra se encuentra dispersa por el resto del territorio, llegando a los municipios más pequeños con poblaciones generalmente de menos de 1000 habitantes, aunque la mayoría inferior a 500. En estos casos las entidades suelen tener uno o dos socios. En total aglutinan a 101 socios (14,21\%) en casi el 50 \% del total de los municipios, es decir, 77 núcleos. En definitiva, muchos socios en pocos municipios, y muchos municipios con pocos socios. 
Las perspectivas para el futuro, según la tendencia de lo acontecido en los últimos años, son que la presencia de las Rutas del Vino siga siendo mayor en la región, expandiéndose por el espacio y llegando cada vez a más territorios. El interés por el desarrollo de este tipo de actividades se manifiesta en el número de Rutas del Vino en Castilla y León, que ha pasado de tener una en el año 2008 a ocho en el 2019, siendo la región de España con el mayor número, aunque la tercera en cuanto a visitantes, aunque todo parece indicar que se irá incrementando a medida que las rutas de reciente creación se vayan desarrollando, lo que permitirá consolidar a Castilla y León como uno de los destinos enoturísticos más significativos de España, y como un territorio que se encuentre a la altura de las regiones vitivinícolas más emblemáticas del planeta. Todo ello tendrá repercusiones positivas para el medio rural, pues el avance y la expansión del enoturismo va asociado a un importante desarrollo socioeconómico en un medio rural que espera salir de la regresión y el letargo, una situación que lleva sufriendo durante décadas, pero que se ha visto intensificado en los últimos años.

Declaración responsable: Las/os autoras/es declaran que no existe ningún conflicto de interés con relación a la publicación de este artículo. Las/os dos autoras/es (J. Fernández Portela y M.J. Vidal Domínguez) han participado en la revisión bibliográfica, en la redacción del texto, en la elaboración de la cartografía y han realizado el trabajo de campo. 


\section{Bibliografía}

Alant, K., \& Bruwer, J. (2004). Wine tourism behavior in the context of a motivational framework for wine regions and cellar doors. Journal of Wine Research, 15(1), 27-37. Retrieved from: https://www.tandfonline.com/doi/abs/10.1080/0957126042000300308

Alcalá Escamilla, B., \& López López Á. (2017). Zonas con potencial agroturístico en la región citrícola de Nuevo León, México: un análisis a partir del álgebra de mapas. Cuadernos de Turismo, 39, 14-40. https://doi.org/10.6018/turismo.39.290371

Beverland, M.B., \& Bretherton, P.B. (1998). The strategic challenges facing the New Zealand wine industry. Journal of wine research, 9(1), 55-64. https://doi.org/10.1080/09571269808718133

Binimelis Sebastian, J. (2019). La transición post-productivista del sector vitivinícola de Mallorca (1990-2015). Boletín de la Asociación de Geógrafos Españoles, 80, 2725, 137. http://dx.doi.org/10.21138/bage. 2725

Bruwer, J. (2003). South African wine routes: some perspectives on the wine tourism industry's structural dimensions and wine tourism product. Tourism Management, 24(4), 423435. https://doi.org/10.1016/S0261-5177(02)00105-X

Carlsen, J. (2002). Segmentation and profiling of the wine festival visitor marke. In C. Cullen, G. Pickering \& R. Phillips (Coords.), Bacchus to the Future: The Inaugural Brock University Wine Conference (pp. 257-278). St. Catharies: Brock University Press.

Carmichael, B. (2005). Understanding the wine tourism experience for winery visitors in the Niagara Region, Ontario, Canada. Tourism Geographies, 7(2), 185204. https://doi.org/10.1080/14616680500072414

Charters, S., \& Ali-Knight, J. (2002). Who is the wine tourist?. Tourism Management, 23(3), 311319. 10.1016/S0261-5177(01)00079-6

Cinelli Colombini, D. (2015). Wine tourism in Italy. International Journal of Wine Research, 7, 2935. https://doi.org/10.2147/IJWR.S82688

Cordeiro Gonçalves, E.C. (2012). Rotas de vino e desenvolvimento Regional. Rotur/Revista de $\begin{array}{lllll}\text { Ocio } & y & \text { Turismo, } & \text { Retrieved }\end{array}$ from http://revistas.udc.es/index.php/rotur/article/view/1258/335 
Correia, R., \& Brito, C. (2016). Wine tourism and regional development. In M. Peris-Ortiz, M.C. Del Río Rama \& C. Rueda-Armengot (Eds.), Wine and tourism: a strategic segment for sustainable economic development (pp. 27-39). Heidelberg: Springer International Publishing.

Del Rey Poveda, A., Cebrián, M., \& Ortega, J.A. (2009). Despoblamiento y envejecimiento en Castilla y León durante el siglo XX: análisis a través de la emigración femenina y la pérdida de nacimientos. Ager: Revista de estudios sobre despoblación y desarrollo rural, 8, 113-150. Retrieved from: https://recyt.fecyt.es/index.php/AGER/article/view/12786/8096

Delgado Urrecho, J.M., \& Martínez Fernández, L.C. (2017). Envejecimiento y desequilibrios poblacionales en las regiones españolas con desafíos demográficos. Ería, Revista cuatrimestral de Geografía, 31(1), 21-43. https://doi.org/10.17811/er.1.2017.21-43

Dodd, T. (2000). Influences on cellar door sales and determinants of wine tourism success: results from Texas wineries. In C.M. Hall (Eds.), Wine Tourism around the World. Development, Management and Markets (pp. 136-149). Oxford: Butterworth Heinemann.

Fernández Fernández, A., \& Fernández Portela, J. (2019). Paisajes y Turismo. Madrid: UNED.

Fernández Portela, J. (2011). Distribución y difusión espacio-temporal de la política de desarrollo rural en Castilla y León: de la iniciativa LEADER I al LEADERCAL (1991-2013). Cuadernos de Geografía, 89, 49-70. Retrieved from

https://dialnet.unirioja.es/servlet/articulo?codigo $=4061754$

Fernández Portela, J. (2014). La distribución de la superficie de viñedo en Castilla y León según sus variables topográficas. Anales de Geografía de la Universidad Complutense, 34(2), 46-63. Retrieved from https://revistas.ucm.es/index.php/AGUC/article/view/47072

Ferreira, S.L.A. \& Hunter, C.A. (2017). Wine tourism development in South Africa: a geographical analysis. Tourism Geographies, 19(5), 676698. https://doi.org/10.1080/14616688.2017.1298152

Frochot, I. (2000). Wine tourism in France: a paradox? In C.M. Hall \& Sharples, L. (Eds.), Wine tourism around the world: development, management and markets (pp. 67-80). New York: Routledge Taylor \& Francis Group.

García Fernández, R. (2016): El desarrollo de Castila y León en la perspectiva de la Estrategia europea 2020. Papeles de economía española, 148, 77-89. Retrieved from https://dialnet.unirioja.es/servlet/articulo?codigo $=5443694$ 
García López, A.M. (2008). El sistema enoturístico español: nuevos productos al servicio de la cultura y el turismo. In Investigaciones turísticas. Una perspectiva multidisciplinar (1-12). I Jornadas de Investigación en Turismo. Sevilla, 7 y 8 de mayo de 2008. Retrieved from https://idus.us.es/xmlui/handle/11441/53589

Getz, D. (2000). Explore Wine Tourism. Management, Development and Destinations. New York: Cognizant Communication Corporation.

González González, M.L. (1997). Desarticulación del mundo rural: el envejecimiento en Castilla y León. Estudios Geográficos, 58(226), Retrieved from: http://estudiosgeograficos.revistas.csic.es/index.php/estudiosgeograficos/article/view/61 $\underline{9 / 659}$

González-Leonardo, M., \& López Gay, A. (2019). Emigración y fuga de talento en Castilla y León. Boletín de la Asociación de Geógrafos Españoles, 80, 2612, 131. http://dx.doi.org/10.21138/bage.2612

González Morales, A., Ramón Ojeda, A., \& Hernández Torres, S. (2015). El cultivo del viñedo como recurso turístico cultural: el caso de La Geria (Lanzarote, Islas Canarias, España). Papeles de Geografía, 61, 109-121. Retrieved from: http://hdl.handle.net/10201/47628

Goulart Rocha, F., \& Tulla, A.F. (2015). Turismo agroalimentario en áreas de cultivo de manzana en la región sur de Brasil. Cuadernos de Turismo, 35, 211229. https://doi.org/10.6018/turismo.35.221581

Hall, C. M., \& Macionis, N. (1998). Wine tourism in Australia and New Zealand. In R. Butler, M. Hall \& J. Jenkins (Eds.), Tourism and recreation in rural areas (pp. 197-224). Chichester: John Wiley \& Son Ltd.

Hall, C. M. \& Mitchell, R. (2008). Wine Marketing: a Practical Guide. Oxford: Elsevier Ltd.

Hortelano Mínguez, L.A. (2015). Desarrollo rural y turismo en Castilla y León: éxitos y fracasos. (Doctoral dissertation). Universidad de Salamanca. Retrieved from hittps://gredos.usal.es/jspui/handle/10366/128441

López Sánchez, J.A. (2010). Posibilidades de desarrollo del enoturismo en la denominación de origen Jerez-Xerry-Sherry y manzanilla de Sanlúcar de Barrameda y Vinagre de Jerez. Boletín de la Asociación de Geógrafos Españoles, 53, 21-41. Retrieved from https://www.agegeografia.es/ojs/index.php/bage/article/view/1191/1114 
Martínez Puche, A., \& Morales Yago, F.J. (2016): El vino como recurso turístico para el fomento del desarrollo local: una oportunidad para las comarcas del Vinalopó (Alicante) y el Altiplano Yecla-Jumilla (Murcia). Cuadernos de Turismo, 38, 267300. https://doi.org/10.6018/turismo.38.271451

Mitchell, R., \& Hall, C. M. (2006). Wine tourism research: the state of play. Tourism Review International, 9, 307-332. Retrieved from

https://www.ingentaconnect.com/contentone/cog/tri/2006/00000009/00000004/art0000 $\underline{2}$

Millán Escriche, M. (2012). Turismo de interior en la Región de Murcia. Una aproximación al turismo rural y al enoturismo. Polígonos. Revista de Geografía, 23, 87112. https://doi.org/10.18002/pol.v0i23.536

Millán Vázquez de la Torre, G., \& Dancausa Millán, M.G. (2012). El desarrollo turístico de zonas rurales en España a partir de la creación de rutas del vino: un análisis DAFO. Teoría y praxis, 12, 52-79. https://doi.org/10.22403/UQROOMX/TYP12/03

Ministerio de Fomento; DG de Arquitectura, Vivienda y Suelo; SG de Suelo, Información y Evaluación (2018): Áreas urbanas en España 2018. Constitución, Cuarenta años de las ciudades españolas. Madrid, Ministerio de Fomento, Secretaría General Técnica, Centro de Publicaciones. Retrieved from

https://apps.fomento.gob.es/CVP/handlers/pdfhandler.ashx?idpub=BAW058

Miranda Escolar, B., \& Fernández Morueco, R. (2011). Vino, turismo e innovación: las Rutas del Vino de España, una estrategia integrada de desarrollo rural. Estudios de Economía Aplicada, Vol. 29(1), 129-164. Retrieved from http://revistas.udc.es/index.php/rotur/article/view/1260/338

Molleví Bortoló, G., \& Fusté Forné, F. (2016). El turismo gastronómico, rutas turísticas y productos locales: el caso del vino y el queso en Cataluña. Geographicalia, 68, 2547. http://dx.doi.org/10.26754/ojs_geoph/geoph.2016681580

Nogué i Font, J., \& San Eugenio Vela, J. (2017). The visual landscape's contribution to generating territorial brands. Boletín de la Asociación de Geógrafos Españoles, 74, 143160. http://dx.doi.org/10.21138/bage.2448

Pardo Abad, C.J. (2013). Territorio y recursos turísticos. Análisis geográfico del turismo en España. Madrid: Editorial Universitaria Ramón Areces, UNED 
Piqueras Haba, J. (2014). Historia de la vid y el vino en España: Edades Antigua y Media. Valencia: Universitat de Valencia.

Plaza Tabasco, J.J., Cañizares Ruiz, M.C., \& Ruiz Pulpón, A.R. (2017). Patrimonio, viñedo y turismo: recursos específicos para la innovación y el desarrollo territorial de Castilla-La Mancha. Cuadernos de Turismo, 40, 547-571. https://doi.org/10.6018/turismo.40.310101

Ponce Sánchez, M.D. (2009). Agroturismo y desarrollo rural en destinos turísticos del interior. El caso de Finca Hacienda Los Granadicos en Moratalla (Murcia). Cuadernos de Turismo, 24, 193206. Retrieved from: https://revistas.um.es/turismo/article/view/92711

Ramírez Montañez, J. (2014). El turismo en el desarrollo regional: la experiencia de dos departamentos colombianos. Revista Lebret, 6, 259-278. Retrieved from http://revistas.ustabuca.edu.co/index.php/LEBRET/article/view/1457/1155

Rodríguez García, J. López-Guzmán, T., \& Sánchez Cañizares, S.M. (2010). Análisis del desarrollo del enoturismo en España. Un estudio de caso. Cultur, Revista de Cultura e Turismo, 4(2), 51-68. Retrieved from: http://periodicos.uesc.br/index.php/cultur/article/view/262

Sánchez Martínez, J.D., \& Ortega Ruiz, A. (2016). El monocultivo olivarero jiennense: conformación histórica, valores patrimoniales y proyección cultural-turística. Cuadernos de Turismo, 37, 377-402. https://doi.org/10.6018/turismo.37.256281

Sharples, L. (2002). Wine tourism in Chile: a brave new step for a brave new world. International Journal of Wine Marketing, 14(2), 43-53. https://doi.org/10.1108/eb008742

Taylor, R. (2007). A review of Global Wine Tourism Research. Journal of Wine Research, 15(1), 5-13. https://doi.org/10.1080/0957126042000300281

Valenzuela Rubio, M. (Coord.) (1997). Los turismos de interior. El retorno de la tradición viajera. Madrid: Ediciones de la UAM.

Vidal Domínguez, M.J., \& Fernández Portela, J. (2014): Castilla y León la comunidad más envejecida de España: perspectiva actual. In Cambio demográfico y socio territorial en un contexto de crisis (pp. 95-107). Actas del XIV Congreso Nacional de Población, AGE. Sevilla, 10, 11 y 12 de septiembre de 2014. Retrieved from: https://agepoblacion.org/congresos,_anteriores/sevilla,-2014.html

Vieira Rodríguez, A., López-Guzmán, T., \& Rodríguez García, J. (2012). Desarrollo socioeconómico endógeno-local y enoturismo: el Marco de Jerez-Sherry (España). 
Desenvolvimento

62. https://doi.org/10.24302/drd.v2i2.231

Woods, M. (2005). Rural geography: Processes, responses and experiences in rural restructuring. London: SAGE Publications Ltd.

Zárate Martín, A., \& Rubio Benito, M.T. (2005). Geografía Humana. Madrid: Editorial Universitaria Ramón Areces. 